OPEN ACCESS

Edited by:

Jianxun Ding,

Changchun Institute of Applied

Chemistry (CAS), China

Reviewed by:

Da Huang,

Fuzhou University, China

Yun Qian,

Shanghai Sixth People's

Hospital, China

Wuyu Zhang,

University of Louisville,

United States

Dongsheng Liu,

Tsinghua University, China

*Correspondence:

Jia-Kuo Yu

yujiakuo@126.com

${ }^{\dagger}$ These authors have contributed equally to this work

Specialty section:

This article was submitted to Translational Pharmacology,

a section of the journal

Frontiers in Pharmacology

Received: 20 October 2019

Accepted: 27 November 2019

Published: 14 January 2020

Citation:

Yan X, Chen $Y-R$, Song $Y-F$, Yang $M$,

Ye J, Zhou G and Yu J-K (2020)

Scaffold-Based Gene Therapeutics for Osteochondral Tissue Engineering.

Front. Pharmacol. 10:1534. doi: 10.3389/fphar.2019.01534

\section{Scaffold-Based Gene Therapeutics for Osteochondral Tissue Engineering}

\author{
Xin Yan ${ }^{1 \dagger}$, You-Rong Chen ${ }^{1+}$, Yi-Fan Song ${ }^{1+}$, Meng Yang ${ }^{1}$, Jing Ye $^{1}$, Gang Zhou ${ }^{2}$ \\ and Jia-Kuo $\mathrm{Yu}^{1 *}$ \\ ${ }^{1}$ Knee Surgery Department of the Institute of Sports Medicine, Peking University Third Hospital, Beijing, China, ${ }^{2}$ Key \\ Laboratory for Biomechanics and Mechanobiology of Ministry of Education, School of Biological Science and Medical \\ Engineering, Beihang University, Beijing, China
}

Significant progress in osteochondral tissue engineering has been made for biomaterials designed to deliver growth factors that promote tissue regeneration. However, due to diffusion characteristics of hydrogels, the accurate delivery of signaling molecules remains a challenge. In comparison to the direct delivery of growth factors, gene therapy can overcome these challenges by allowing the simultaneous delivery of growth factors and transcription factors, thereby enhancing the multifactorial processes of tissue formation. Scaffold-based gene therapy provides a promising approach for tissue engineering through transfecting cells to enhance the sustained expression of the protein of interest or through silencing target genes associated with bone and joint disease. Reports of the efficacy of gene therapy to regenerate bone/cartilage tissue regeneration are widespread, but reviews on osteochondral tissue engineering using scaffold-based gene therapy are sparse. Herein, we review the recent advances in gene therapy with a focus on tissue engineering scaffolds for osteochondral regeneration.

Keywords: microRNAs, gene therapy, scaffold, tissue engineering, osteochondral regeneration

\section{INTRODUCTION}

Articular osteochondral injury is a common and frequently occurring disease in orthopedics, mainly caused by accidental trauma, sports injury or arthritis. Mature articular cartilage has a very weak ability to resist injury and disease, and has limited self-repair ability. After the articular cartilage is damaged, it cannot be effectively repaired, eventually leading to the occurrence of osteoarthritis (OA). It is expected that by 2030, OA will be the most common chronic degenerative joint disease among aging populations (Thomas et al., 2014; Tsezou, 2014). OA patients often suffer from severe pain and limited mobility. OA is also considered the leading cause of disability in the general population. The regeneration of articular cartilage that lacks self-healing ability is a major challenge in clinical treatment and clinically available methods fail to meet long-term effective regeneration requirements. This has caused concern in the field of osteochondral tissue engineering in which new tissues can be engineered to promote joint regeneration and prevent the onset of OA (Zhang et al., 2019). One promising approach is the treatment of genes delivered by tissue engineering scaffolds. By transfecting specific gene sequences into seed cells, overexpressing or silencing the original gene, the biological function of the cells could be regulated to obtain the desired effect. Gene therapy 
combined with tissue engineering scaffolds provides a more precise, controlled, and sustained release of therapeutic factors compared to traditional methods of delivering growth factors directly (Figure 1). This review focuses on recent advances in gene therapy in the field of scaffold-based osteochondral tissue engineering. In terms of miRNAs, we focus on recent research progress related to $\mathrm{OA}$ in the hope that miRNA can be used in the future gene therapy approaches combined with scaffoldbased osteochondral tissue engineering.

\section{OSTEOCHONDRAL TISSUE ENGINEERING}

Tissue engineering uses bionic scaffold to simulate the cell growth microenvironment and combines the body's selfhealing ability to guide tissue regeneration in damaged or defective tissue sites. The cell microenvironment of tissue engineering bionics can induce cartilage or the osteogenic differentiation of stem cells, promoting their proliferation and migration, leading to endogenous osteochondral regeneration ( $\mathrm{Li}$ et al., 2016). Osteochondral tissue engineering has evolved to enhance cell proliferation, differentiation, migration, and survival by transmitting growth factors and signaling molecules. These ligands combined with cell surface receptors of mesenchymal stem cells or mesenchymal progenitors, activate signaling pathways that promote osteochondral regeneration. However, the short half-life of recombinant proteins, such as BMPs, low bioactivity and high preparation costs lead to the exploration of new methods to deliver bioactive osteochondral regenerative compounds (Shi et al., 2014). A promising area is the use of scaffold-based gene therapy. By introducing specific gene sequences into cells, it is possible to modify or replace existing genes and regulate their epigenetic functions to achieve a desired purpose (Ginn et al., 2018). Gene-activated scaffolds provide a continuously controlled method of nucleic acid therapy to achieve a more efficient and safe release of biological agents.

\section{Scaffold Biomaterials}

To promote tissue regeneration, the osteochondral scaffold must be biocompatible, have a suitable rate of degradation, and possess a porous structure (Wang et al., 2019a). To-date, osteochondral tissue engineering biomaterials include natural polymers, synthetic polymers, metals, and inorganic materials. Natural materials are derived from animals, plants, and microorganisms and can be classified into protein, polysaccharide, polyester, and polyamide based polymers according to their chemical composition (Nooeaid et al., 2012; Liu et al., 2018). The natural biological function and ability to promote cell adhesion and proliferation are unique advantages of natural polymer materials such as collagen, gelatin, and chitosan (Nooeaid et al., 2012; Kowalczewski and Saul, 2018). The variability and low mechanical strength of different batches of natural biomaterials lead to inevitable defects (Hsu et al., 2010). In contrast, mechanical properties can be carefully controlled through structural and surface modifications using synthetic polymers (Shimomura et al., 2014). However, because of its inherent hydrophobicity and lack of binding sites, their cell adhesion ability is relatively poor (Sarasam et al., 2006; Antonova et al., 2016). Another important consideration when designing osteochondral scaffolds is that the rate of degradation of biomaterials should match the rate of tissue repair. There are significant differences in the rates at which enzymes degrade natural polymers at different transplant sites in vivo, depending on the activity and concentration of the enzyme under different conditions. Conversely, hydrolytically degradable synthetic polymers show minor differences between sites or patients compared to enzymatically degradable polymers. However, the by-products of degradation are toxic (Zhang et al., 2014). Bioceramics, such as calcium phosphate, are characterized by their excellent osteoinductivity. Common types of bone calcium scaffolds are hydroxyapatite, tricalcium phosphate, biphasic calcium phosphate, and multiphase bioglass. By changing the composition of $\mathrm{Ca}_{3}\left(\mathrm{PO}_{4}\right)_{2}$ ceramics, the stability and mechanical properties of the materials can be modified (Lima et al., 2019).

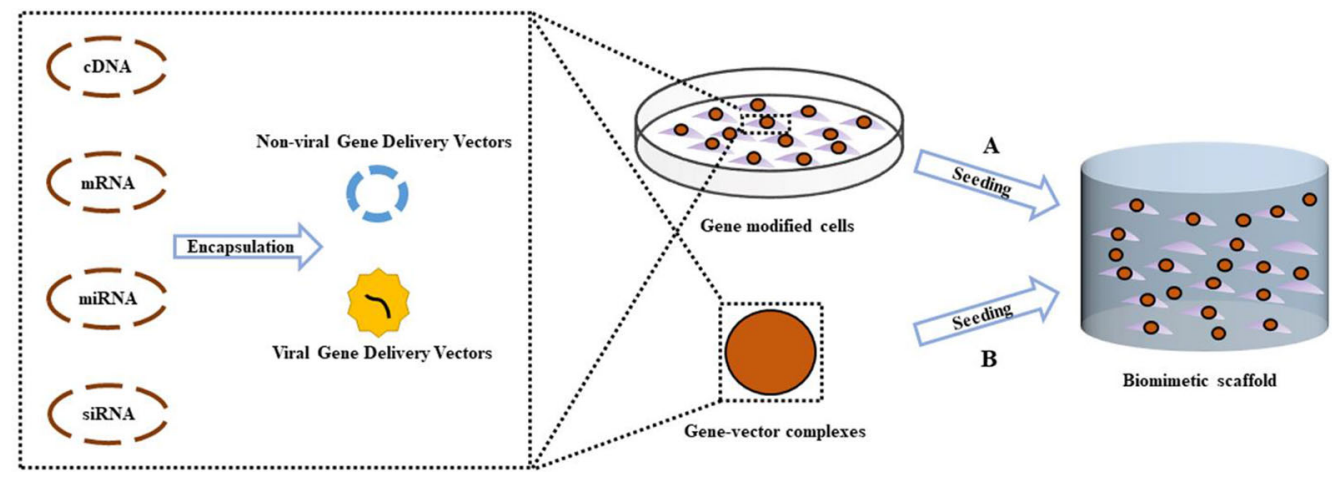

FIGURE 1 | Scheme of gene activated scaffold. Specific gene sequences were encapsulated into gene delivery vectors (Non-viral or viral), forming gene-vector complexes. (A) Exogenous seed cells were modified by uptake of gene-vector complexes, then were seeded into biomimetic scaffold supporting for the formation of new tissue. (B) The gene-vector complexes were loaded directly into the scaffold. Endogenous seed cells around the osteochondral defect migrate into the scaffold and take in specific genes in the gene-vector complexes, promoting chondrogenic or osteogenic differentiation. 
However, separate scaffold biomaterials are not effective in promoting osteochondral tissue repair. To increase the number of cells and the chondrogenesis/osteogenesis of MSCs, an array of cellular factors can be applied to the scaffold to promote and maintain the production of cartilage ECM.

\section{Biochemical Factors}

Bone morphogenetic proteins (BMPs) (Reyes et al., 2014), fibroblast-growth-factor 2 (FGF-2) (Yi et al., 2012), transcriptional SOX proteins (Cao et al., 2011), nel-like molecule-1 (Nell-1) (Zhang et al., 2016b; Wang et al., 2017), and IGF-1 and IGF-2 promote cartilage formation (Wang et al., 2009) and osteogenic differentiation. In addition, as angiogenic factors, Platelet derived growth factors (PDGF), vascular endothelial growth factor (VEGF), and early growth response gene 1 (EGR1) promote bone repair (Franses et al., 2010; Press et al., 2015; Sheng et al., 2018). As anti-angiogenic factor, chondromodulin 1 (CHM-1) not only stimulates chondrogenesis but also inhibits chondrocyte hypertrophy and endochondral ossification (Klinger et al., 2011). A common route of administration for general growth factors is intravenous injection. However, the growth factor in the blood has a short half-life. By adjusting the physicochemical properties of the scaffold to slow release of growth factors, the drawbacks of direct administration can be avoided. Although 3D scaffolds can function as sustained-release growth factors, their ability to promote perivascular tissue healing and stem cells (SCs) regeneration is limited by their localization. Scaffold-based gene therapy provides a promising approach for tissue engineering through transfecting specific nucleic acids into cells to enhance the sustained expression of the growth factors of interest or through silencing target genes associated with bone and joint disease

\section{MicroRNAs Cartilage}

MicroRNAs (MiRNAs) are 22 nucleotide single stranded RNAs that regulate post-transcriptional gene expression. MiRNA induces degradation of the target mRNA by binding to the $3^{\prime}$ untranslated region (UTR) complementary sequence on messenger RNA (mRNA), inhibiting translation, thereby suppressing corresponding protein production. Unlike small interfering RNA (siRNA), which regulates only one specific target, miRNA can regulate multiple targets. A single miRNA can regulate different targets in multiple signaling pathways, so it is more advantageous than other biomolecules in terms of functional effects. MiRNA expression profiles are significantly different during the development of articular cartilage, chondrocyte differentiation, and MSC chondrogenesis. Chondrocyte miRNA profiles differ from normal chondrocytes during their degeneration during osteoarthritis (OA). These miRNAs involved in chondrocyte differentiation or degeneration may be used in bioscaffolds in future studies to participate in the regeneration of cartilage tissue. The following is a summary of their latest.

MiRNAs regulate chondrocyte signaling and epigenetic functions (Cong et al., 2017b). Among the miRNAs, miR-210 targets the death receptor-6 (DR6) and inhibits NF- $\mathrm{KB}$ signaling in cultured chondrocytes and OA animal models. In addition, by inhibiting karyopherin subunit alpha-3 (KPNA3) gene expression, MiR-26a/MiR-26-b regulate the translocation of NF-KB-p65 to the nucleus (Mirzamohammadi et al., 2014), and their inhibition leads to enhanced COX-2 and MMP-3, -9, -13 expression (Yin et al., 2017). MiR-138 expression is low in OA cartilage compared to normal cartilage whilst p65 is targeted by miR-138 during OA progression (Wei et al., 2017). MiR-27a3 p levels are also lower in OA cartilage (Li et al., 2018a) while miR-139 is highly expressed and inhibits cell viability and migration by inhibiting the expression of EIF4G2 and IGF1R. MiR-139 inhibitors show the opposite effect (Hu et al., 2016).

Through its ability to target FUT1, microRNA-149-5p promotes the proliferation and survival of chondrocytes, thus preventing OA. It has also been found to be downregulated in patients with $\mathrm{OA}$, leading to degenerative cartilage and disturbing homeostasis. Carriers have been employed to deliver miRNA-149-5p to MSCs to promote chondrogenesis (Celik et al., 2019). MiR-218 is highly expressed early in cartilage formation, but is stopped in synaptic-derived mesenchymal stem cells (SDSC) at the maturation stage of cartilage differentiation and miR-218 may directly regulates 15hydroxyprostaglandin dehydrogenase expression in SDSCs (Chen et al., 2019c). MiR-320c was decreased in the later stages of chondrogenesis of adipose-derived stem cells (hADSCs) and OA chondrocytes. It inhibits degeneration of OA chondrocytes by directly targeting beta-catenin and inhibiting Wnt signaling ( $\mathrm{Hu}$ et al., 2019). MiR-92a-3p expression was increased in MSC chondrogenic exosomes and significantly decreased in OA chondrocytes exosomes. MiR-92a$3 \mathrm{p}$ may be involved in regulating cartilage development by targeting WNT5A (Mao et al., 2018b). Conversely, miR-182-5p plays a negative role in BM-MSC chondrogenesis by downregulating parathyroid hormone-like hormone (PTHLH) (Bai et al., 2019). Table 1 summarizes the miRNAs, related to cartilage development, that have been studied in recent years.

\section{Subchondral Bone}

The subchondral bone layer below the cartilage in a joint acts as a shock absorber to absorb stress, cushion vibrations, and maintaining joint shape. Studies have shown that subchondral bone remodeling runs through the entire pathogenesis of $\mathrm{OA}$ (Aho et al., 2017) via the activities of two main cell populations, osteoblasts (OBs) that promote bone formation and osteoclasts (OCs) that promote bone resorption. OBs originate from MSC precursors mainly through BMPs, Wnt, TGF- $\beta$ signals. OCs originate from peripheral blood mononuclear cell (PBMC) precursors mainly by the effects of RANKL/OPG ratio. Bone remodeling and osteoclast differentiation are controlled by miRNAs (Taipaleenmaki, 2018). MiR-135-5p promotes osteogenesis through its ability to enhance the activity of alkaline phosphatase (ALP), upregulate calcification molecules, and target the Hypoxia inducible factor 1 alpha inhibitor (HIF1AN) (Yin et al., 2019). Conversely, MiR-145 suppresses human jaw bMSC osteogenic differentiation through $W N T / \beta$ catenin signaling and semaphorin3A (SEMA3A) targeting (Jin et al., 2019). Similarly, MiR-494 suppresses osteoblast 
TABLE 1 | Summary of the miRNAs associated with cartilage development and homeostasis.

\begin{tabular}{|c|c|c|c|c|c|}
\hline miRNA & Targets gene & In vitro/in vivo & Cells/vivo model & Biological effect & Reference \\
\hline miR-9-5p & Tnc & In vitro, in vivo & Mice chondrocytes, mice & Regulates cartilage homeostasis & (Chen et al., 2019a) \\
\hline $\operatorname{miR}-10 a-5 p$ & HOXA1 & In vitro, in vivo & Mice chondrocytes, mice & Regulates cartilage homeostasis & (Ma et al., 2019b) \\
\hline $\operatorname{miR}-16-5 p$ & SMAD3 & In vitro & Human chondrocytes & Regulates cartilage homeostasis & (Li et al., 2015) \\
\hline miR-21-5p & FGF18 & In vitro, in vivo & Human chondrocytes, mice & Regulates cartilage homeostasis & (Wang et al., 2019b) \\
\hline miR-27a & PI3K & In vitro & SW1353 & Regulates cartilage homeostasis & (Cai et al., 2019) \\
\hline miR-30a & DLL4 & In vitro & Rat MSC & Enhance chondrogenesis & (Tian et al., 2016) \\
\hline miR-34a & Cyr61 & In vitro & Human chondrocytes & Regulates cartilage homeostasis & (Yang et al., 2018a) \\
\hline \multirow[t]{2}{*}{ miR-92a-3p } & ADAMTS4/5 & In vitro & Human MSC & Enhance chondrogenesis & (Mao et al., 2017a) \\
\hline & HDAC2 & In vitro & Human MSC & Enhance chondrogenesis & (Mao et al., 2017b) \\
\hline \multirow[t]{2}{*}{ miR-93 } & TCF4 & In vitro, in vivo & Human chondrocytes, rabbit & Regulates cartilage homeostasis & (Xue et al., 2019) \\
\hline & TLR4 & In vitro, in vivo & Mice chondrocytes, mice & Regulates cartilage homeostasis & (Ding et al., 2019) \\
\hline miR-95-5p & HDAC2/8 & In vitro & Human chondrocytes & Regulates cartilage homeostasis & (Mao et al., 2018a) \\
\hline miR-98 & $\mathrm{Bcl}-2$ & In vivo & Rats & Regulates cartilage homeostasis & (Wang et al., 2016) \\
\hline miR-107 & HMGB-1 & In vitro, in vivo & Human chondrocytes, rabbit & Regulates cartilage homeostasis & (Lin et al., 2019) \\
\hline miR-127-5p & Runx2 & In vitro & Rat BMSCs & Enhance chondrogenesis & (Xue et al., 2017) \\
\hline miR-138 & $\mathrm{HIF}-2 \alpha$ & In vitro & Human chondrocytes & Inhibit chondrogenesis & (Seidl et al., 2016) \\
\hline miR-140-5p & Smad3 & In vitro & Mandibular condylar chondrocytes & Regulates cartilage homeostasis & (Li et al., 2019c) \\
\hline miR-145 & MKK4 & In vitro, in vivo & Rat chondrocytes, rat & Regulates cartilage homeostasis & (Hu et al., 2017) \\
\hline miR-145-5p & SOX9 & In vitro & Human BMSC & Inhibit chondrogenesis & (Verbus et al., 2017) \\
\hline $\operatorname{miR}-146 a-5 p$ & CXCR4 & In vitro & Human chondrocytes & Regulates cartilage homeostasis & (Jia et al., 2019) \\
\hline \multirow[t]{2}{*}{ miR-146b } & AM & In vitro, in vivo & Mice chondrocytes, mice & Regulates cartilage homeostasis & (Liu et al., 2019b) \\
\hline & SOX5 & In vitro & Human Skeletal stem cells & Inhibit chondrogenesis & (Budd et al., 2017) \\
\hline miR-149-5p & FUT-1 & In vitro & Human MSC & Enhance chondrogenesis & (Celik et al., 2019) \\
\hline miR-181a-5p & SBP2 & In vitro & SW1353 & Regulates cartilage homeostasis & (Xue et al., 2018) \\
\hline $\operatorname{miR}-193 b-3 p$ & HDAC3 & In vitro, in vivo & hMSC, PHCs, nude mice & $\begin{array}{l}\text { Enhance chondrogenesis, } \\
\text { Regulates cartilage homeostasis }\end{array}$ & (Meng et al., 2018) \\
\hline $\operatorname{miR}-221-3 p$ & SDF1 & In vitro & SW1353 & Regulates cartilage homeostasis & (Zheng et al., 2017) \\
\hline miR-222 & HDAC-4 & In vitro, in vivo & Human chondrocytes, mice & Regulates cartilage homeostasis & (Song et al., 2015) \\
\hline miR-320 & MMP-13 & In vitro & Mice chondrocytes & Enhance chondrogenesis & (Meng et al., 2016) \\
\hline miR-322 & MEK1 & In vitro, in vivo & Mice chondrocytes, mice & Enhance chondrogenesis & (Bluhm et al., 2017) \\
\hline $\operatorname{miR}-365$ & HDAC4 & In vitro, in vivo & Rat BMSCs, rats & Enhance chondrogenesis & (Chen and Wu, 2019) \\
\hline miR-384-5p & SOX9 & In vitro, in vivo & Mice chondrocytes, mice & Regulates cartilage homeostasis & (Zhang et al., 2018) \\
\hline $\operatorname{miR}-410$ & Wnt3a & In vitro & Human BMSC & Enhance chondrogenesis & (Zhang et al., 2017) \\
\hline miR-411 & MMP-13 & In vitro & Human chondrocytes & Regulates cartilage homeostasis & (Wang et al., 2015) \\
\hline $\operatorname{miR}-483$ & SMAD4 & In vitro & Human BMSC & Enhance chondrogenesis & $\begin{array}{l}\text { (Anderson and } \\
\text { McAlinden, 2017) }\end{array}$ \\
\hline $\operatorname{miR}-526 b-3 p$ & SMAD7 & In vitro & Human BMSC & Enhance chondrogenesis & (Wu et al., 2018) \\
\hline
\end{tabular}

Thc, tenascin C; AM, alpha-2-macroglobulin; HMGB-1, high mobility group box 1; CXCR4, C-X-C chemokine receptor type 4; TLR4, toll-like receptor 4; SBP2, sequence binding protein 2; SW1353, human chondrosarcoma chondrocyte; HDAC2/8, histone deacetylase 2/8; hMSC, human mesenchymal stem cell; PHCs, primary human chondrocytes; Cyr61, cysteine-rich angiogenic inducer 61; MKK4, mitogen-activated protein kinase 4; CXCL12, C-X-C motif chemokine ligand 12; MEK1, mitogen-Activated Protein Kinase 1; DLL4, delta-like 4; MMP-13, metalloproteinase 13; HIF-2 $\alpha$, hypoxia-inducible factor $2 \alpha$.

differentiation by BMPR-SMAD-RUNX2 signal simulated by microgravity (Qin et al., 2019). MiR-877-3p targets Smad7 to enhance TGF- $\beta 1$ mediated MC3T3-E1 cell differentiation ( $\mathrm{He}$ et al., 2019). MiR-200c also enhances osteogenic differentiation of hBMSCs by regulating AKT/ $\beta$-Catenin signaling through the inhibition of myeloid differentiation factor 88 (Myd88) (Xia et al., 2019). In human ADSCs, miR-125a-3p could negatively modulates osteoblastic differentiation via targeting Smad4 and Jak1. John et al. found that miR-487b-3p suppressed osteoblast differentiation by targeting Notch-regulated ankyrin-repeat protein (Nrarp), which in turn, suppresses Runx-2 and Wnt signaling (John et al., 2019). In BMSCs, miR-206 inhibits osteogenic differentiation through regulating glutamine metabolism (Chen et al., 2019d). MiR-223 is a newly discovered miRNA that induces MC3T3-E1 differentiation via HDAC2 targeting (Chen et al., 2019b). A complete summary is shown in Table 2.

Similar to osteoblast differentiation, the expression pattern of miRNAs related with the osteoclast differentiation has also been deeply explored (Hrdlicka et al., 2019). MiR-363-3p activated by MYB enhances osteoclast differentiation and inhibits osteoblast differentiation via the PI3K-AKT-PTEN axis (Li et al., 2019a). MiR-1225 suppresses TNF $\alpha$-induced osteoclast differentiation through Keap1-Nrf2-HO-1 signal via ROS generation in bone marrow-derived macrophages (BMMs) (Reziwan et al., 2019). Conversely, miR-142-5p targets PTEN and induces BMM osteoclastogenesis (Lou et al., 2019). In addition, Smad3 expression is reduced by miR-145, the mimics of which in OVX mice repress OCs (Yu et al., 2018). MiR-125a-5p promotes osteoclast differentiation through inhibiting TNFRSF1B expression (Sun et al., 2019a). Sun and colleagues showed that miR-338-3p enhances the differentiation of Ocs by targeting Mafb (Sun et al., 2019b) that is also a target for miR199a-5p (Guo et al., 2018). Wang et al. found that miR-218 decreased osteoclastogenic differentiation via suppressing NF- $\kappa \mathrm{B}$ signal via targeting TNFR1 (Wang et al., 2018b). Recent studies have shown that miR-133a promotes postmenopausal osteoporosis through enhancing OC differentiation (Li et al., 
TABLE 2 | Summary of recently identified miRNAs associated with osteogenesis.

\begin{tabular}{|c|c|c|c|c|c|}
\hline miRNA & Targets gene & In vitro/in vivo & Cells/vivo model & Biological effect & Reference \\
\hline miR-16-2-3p & WNT5A & In vitro & hBMSCs & Inhibit osteogenic differentiation & (Duan et al., 2018) \\
\hline miR-21-5p & SMAD7 & In vitro & МС3Т3-E1 & Promote osteoblast differentiation & (Li and Jiang, 2019) \\
\hline miR-27b & PPAR & In vitro & hBMSCs & Promote osteogenic differentiation & (Seenprachawong et al., 2018) \\
\hline miR-29b & BCL-2 & In vitro & Mice BMSCs & Promote osteoclast differentiation & (Sul et al., 2019) \\
\hline miR-34c & LGR4 & In vitro & Mice BMMs & Promote osteoclast differentiation & (Cong et al., 2017a) \\
\hline miR-92b-5p & ICAM-1 & In vitro, in vivo & Mice BMSCs, mice & Promote osteogenic differentiation & (Li et al., 2019d) \\
\hline miR-96 & SOST & In vitro & Mice osteoblast & Promote osteoblast differentiation & (Ma et al., 2019a) \\
\hline miR-100-5p & FGF21 & In vitro, in vivo & Mice BMMs, mice & Inhibit osteoclast differentiation & (Zhou et al., 2019a) \\
\hline miR-125a-5p & TNFRSF1B & In vitro & RAW 264.7 OPC & Promote osteoclast differentiation & (Sun et al., 2019a) \\
\hline miR-128 & SIRT6 & In vitro & C2C12 cells & Inhibit osteoblast differentiation & (Zhao et al., 2019b) \\
\hline miR-130a & PPAR & In vitro & hBMSCs & Promote osteogenic differentiation & (Seenprachawong et al., 2018) \\
\hline miR-132-3p & Smad5 & In vitro & MC3T3-E1 & Inhibit osteoblast differentiation & (Liu et al., 2019a) \\
\hline miR-135-5p & HIF1AN & In vitro & MC3T3-E1 & Promote osteoblast differentiation & (Yin et al., 2019) \\
\hline miR-139-3p & ELK1 & In vitro & MC3T3-E1 & Inhibit osteoblast differentiation & (Wang et al., 2018c) \\
\hline miR-140-5p & TLR4, BMP2 & In vitro, in vivo & ASCs, rats & Promote osteogenesis & (Guo et al., 2019b) \\
\hline miR-141 & Calcr, EphA2 & In vitro, in vivo & M-BMMs, monkey & Inhibit osteoclast differentiation & (Yang et al., 2018b) \\
\hline miR-142-5p & PTEN & In vitro & Rat BMMs & Promotes osteoclast differentiation & (Lou et al., 2019) \\
\hline miR-144-3p & RANK & In vitro & CD14+PBMC & Inhibit osteoclast differentiation & (Wang et al., 2018a) \\
\hline miR-145 & SEMA3A & In vitro & hJBMMSCs & Inhibit osteoblastic differentiation & (Jin et al., 2019) \\
\hline miR-145-5p & OPG & In vitro, in vivo & RAW-264.7, mice & Promotes osteoclast differentiation & (Chen et al., 2018) \\
\hline miR-146a & M-CSF & In vivo & Mice with OVX & Inhibit osteoblast differentiation & (Zhao et al., 2019a) \\
\hline miR-199a-5p & Mafb & In vitro & RAW 264.7 cells & Promote osteoclast differentiation & (Guo et al., 2018) \\
\hline miR-218-5p & COL1A1 & In vitro & Mice BMSCs & Promote osteoblastic differentiation & (Kou et al., 2019) \\
\hline miR-218 & Mmp9 & In vitro & RAW264.7 cells & Inhibit osteoblastic differentiation & (Guo et al., 2019a) \\
\hline miR-200c & Myd88 & In vitro & hBMSCs & Promote osteogenic differentiation & (Xia et al., 2019) \\
\hline miR-208a-3p & ACVR1 & In vitro, in vivo & MC3T3-E1, mice & Inhibit osteoblastic differentiation & (Arfat et al., 2018) \\
\hline miR-210 & Runx2 & In vitro & HUCB-MSC & Promote osteoblast differentiation & (Asgharzadeh et al., 2018) \\
\hline miR-221 & ZFPM2 & In vitro & MC3T3-E1 & Promote osteoblast differentiation & (Zheng et al., 2018) \\
\hline miR-223-5p & HDAC2 & In vitro, in vivo & МС3Т3-E1, mice & Promote osteoblast differentiation & (Chen et al., 2019b) \\
\hline \multirow[t]{2}{*}{ miR-338-3p } & $\mathrm{IKK} \beta$ & In vitro & RAW264.7 cell & Inhibit osteoclast differentiation & (Niu et al., 2019) \\
\hline & RANKL & In vitro & Mice BMCs & Inhibit osteoclast differentiation & (Zhang et al., 2016a) \\
\hline miR-342-3p & ATF3 & In vitro, in vivo & MC3T3-E1, mice & Promote osteoblast differentiation & (Han et al., 2018) \\
\hline miR-363-3p & PTEN & In vitro & CD14+PBMC & Promote osteoclast differentiation & (Li et al., 2019a) \\
\hline miR-367 & PANX3 & In vitro, in vivo & Mice osteoblast, mice & Promote osteoblast differentiation & (Jia and Zhou, 2018) \\
\hline miR-376c-3p & IGF1R & In vitro & hBMSCs, & Inhibit osteogenic differentiation & (Camp et al., 2018) \\
\hline miR-377 & RANKL & In vitro, in vivo & hBMMs, mice & Inhibit osteoclast differentiation & (Li et al., 2019b) \\
\hline miR-383 & Satb2 & In vitro & Rat BMSCs & Inhibit osteoblastic differentiation & (Tang et al., 2018) \\
\hline miR-494 & BMPR2/RUNX2 & In vitro & C2C12 cells & Inhibit osteoblast differentiation & (Qin et al., 2019) \\
\hline miR-451 & YWHAZ & In vitro, in vivo & hBMSCs, mice & Inhibit osteoblast differentiation & (Pan et al., 2018) \\
\hline miR-487b-3p & Nrarp & In vitro, in vivo & Mice osteoblasts, mice & Inhibit osteoblast differentiation & (John et al., 2019) \\
\hline miR-874 & SUFU & In vitro, in vivo & Rat osteoblasts, rat & Promote osteoblast differentiation & (Lin et al., 2018) \\
\hline miR-877-3p & Smad7 & In vitro & МС3Т3-Е1 & Promote osteoblast differentiation & (He et al., 2019) \\
\hline miR-1225 & Keap1 & In vitro, in vivo & BMMs, mice & Inhibit osteoclast differentiation & (Reziwan et al., 2019) \\
\hline miR-let-7c & SCD-1 & In vitro & hADSCs & Inhibit osteogenic differentiation & (Zhou et al., 2019b) \\
\hline
\end{tabular}

HIF1AN, hypoxia-inducible factor $1 \alpha$ inhibitor; M-CSF, macrophage colony-stimulating factor; OVX, ovariectomy; SEMA3A, semaphorin 3A; h-JBMMSCs, human jaw bone marrow

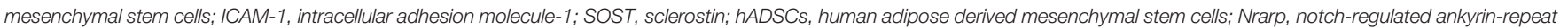

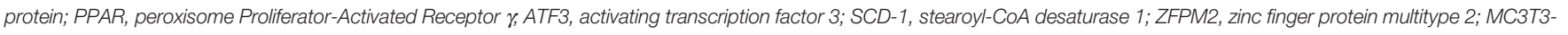
E1, the mouse osteoblast-like cells; SUFU, suppressor of fused gene; IGF1R, insulin growth factor 1 receptor; HUCB, human umbilical cord blood; Satb2, special AT-rich-sequence-

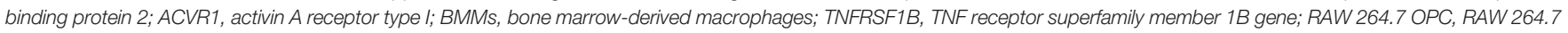

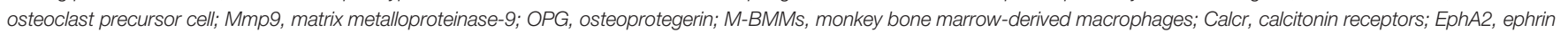
type-A receptor 2 precursor; LGR4, leucine-rich repeat-containing G-protein-coupled receptor 4.

2018b). The culmination of these studies highlight the potential of miRNAs to regulate OC differentiation (Table 2).

\section{VECTOR BASED GENE-DELIVERY}

Tissue-engineering and gene therapy have been used in the treatment of myocardial injuries (Gabisonia et al., 2019), the repair of cartilage defects (Armiento et al., 2018), and the treatment of bone defects (Chen et al., 2019e). Compared with protein-based treatment, gene therapy has two main advantages. Gene therapy is more biologically active and physiological than common recombinant approaches (Raftery et al., 2019). Since the gene fragment itself cannot be efficiently introduced into the cell, an effective vector is required. Gene vectors can be virusbased (lentiviruses or baculoviruses) or non-viral including transfection methods such as lipofectamine, electroporation, and nanoparticles. They all have their own advantages and 
disadvantages, but in general, the transfection efficiency of current viral vectors is still higher than that of non-viral vectors.

\section{Viral Vectors \\ Use of Adenoviruses}

Adenoviral transgenic efficiency is typically close to $100 \%$ in vitro. Adenoviruses can transduce different human tissue cells, dividing and non-dividing. The production of high titer adenoviral vectors is simple and no integration into the genomes of human cells occur. As such, adenoviral vectors have been increasingly used in clinical trials of gene therapy and have become the most promising viral vectors, second only to retroviral vectors. In a recent study, it is found that the use of Adenoviral-BMP-2/basic fibroblast growth factor (bFGF)modified BMMSCs combined with demineralized bone matrix promote bone formation and angiogenesis, successfully repairing canine femoral head necrosis (ONFH) (Peng and Wang, 2017). However, the biggest challenge to the effectiveness of adenoviral approaches are the immune response.

\section{Baculovirus Approaches}

Baculoviruses show no pathogenicity toward humans and can be used under normal biosafety level 2 conditions. Baculoviruses, like adenoviral, induce both dividing and non-dividing cells. In some recent studies, baculoviruses has been used. Lo and colleagues employed Cre/loxP-based baculovirus vectors in adipose-SCs to enhance bone healing (Lo et al., 2017). Fu and coworkers highlighted the ability of baculoviruses to induce osteogenesis through allogeneic-MSCs (Fu et al., 2015). Despite this promise, the transient expression profiles of baculoviruses limit their use. In an attempt to overcome this issue, Chen and coworkers developed baculoviruses hybridized with the miR-155 scaffolds and the sleeping beauty transposon to sustainably inhibit transgene expression for extended time periods (Chen et al., 2011).

\section{Lentiviruses}

The advantage of lentiviral vectors are the high levels of foreign gene integration into the host chromosome in cells typically difficult to transfect, including primary cell cultures. Lentiviral vectors can be combined with chondroitin sulfate-hyaluronic acidsilk fibrin composite scaffolds and applied to bone-ligament connections to promote tissue engineering (Sun et al., 2014). In addition, Brunger et al. developed an independent bioactive scaffold that is capable of inducing stem cell differentiation and cartilage ECM formation using lentiviruses (Brunger et al., 2014). Despite the great progress in the study of lentiviral vector, it is still far from clinical application. First, the titer of recombinant virus is still not up to the level of in vivo application. Second, due to the complex biological properties of HIV, it is difficult to establish a stable HIV vector like the commonly used mouse retroviral vector, and the established packaging cells are not ideal.

\section{Non-Viral Gene Delivery Vectors}

Commercialized cationic lipids such as Lipofectamine 2000, Lipofectamine 3000, Lipofectamine RNAiMAX, and SiPORT NeoFx are widely used in biomaterial-based gene therapy. In recent studies, using lipofectamine 2000, Anti-miR-221 was transfected into adipose-MSCs which were seeded into synthetic nHA/PCL scaffolds. The results indicate that this method provides an effective way to promote osteogenesis of AT-MSCs (Hoseinzadeh et al., 2016). Macmillan et al. combined lipofectamine-complexed plasmids encoding BMP-2 and TGF$\beta 1$ with HA microparticles for delivery to the MSCs of three healthy pig donors. This study provides a promising approach to gene therapy that regulates stem cell growth and development to treat bone defects (McMillan et al., 2018).

Although the toxicity of liposomes are well-known, more efficient transfection methods to replace them have not emerged. Recently, to enhance the interaction between cells and nucleic acids, Raftery et al. developed a new cell penetrating peptide, GET, combined with a variety of collagen scaffolds, which showed good regeneration potential. GET is suitable for all three germ layer cell transfections with efficiencies comparable to Lipofectamine 3000 and minimal cytotoxicity. These findings suggest that GET can be combined with scaffold delivery systems, to provide new solutions to a variety of tissue engineering regenerative indications (Raftery et al., 2019).

\section{GENE THERAPY IN SCAFFOLD BASED OSTEOCHONDRAL TISSUE REPAIR}

Gene therapy for osteochondral tissue repair is divided into two phases: one to locate the gene to the target area directly, either through encapsulation onto a scaffold, or through a specific gene vector (in vivo). Alternatively, the target gene is loaded into the cells by the vectors in vitro, and genetically modified cells are administered to the target lesion area, with or without a scaffold (ex vivo). However, the main obstacle to the treatment of focal defects with non-scaffolds is that the genetically modified cells or gene vectors with intra-articular injections are diluted by the joint fluid and fail to reach the target lesion area. To avoid this drawback, a promising approach is to deliver modified cells or gene vectors using different types of scaffolds. When the scaffold is degraded, the contents are slowly released to the target area. Gene therapy combined with scaffolds increases the efficiency and duration of transfected genes, forming an efficient system to promote osteochondral regeneration. We herein summarize and discuss these gene therapy-binding scaffolds discovered from 2006 to 2019 in the contest of seeding cell types (Figure 2).

\section{Gene Modified BMSCs}

MSCs are the most widely studied due to their high availability and proliferative/differentiation ability. The microenvironment typically dictates the fate of MSCs. BMSCs are more commonly employed than those derived from adipose tissue (AMSCs), particularly for osteochondral therapy. In one study, BMSCs were transfected with hIGF-1 cDNA and mixed with calcium alginate gels for transplantation into $6 \mathrm{~mm}$ osteochondral defects and were found to improve the repair (Leng et al., 2012).

In view of the role of TGF- $\beta$ in promoting cartilage repair, in addition to the inhibition of inflammatory and immune responses, pcDNA-TGF- $\beta$ gene-modified BMSCs were seeded onto 


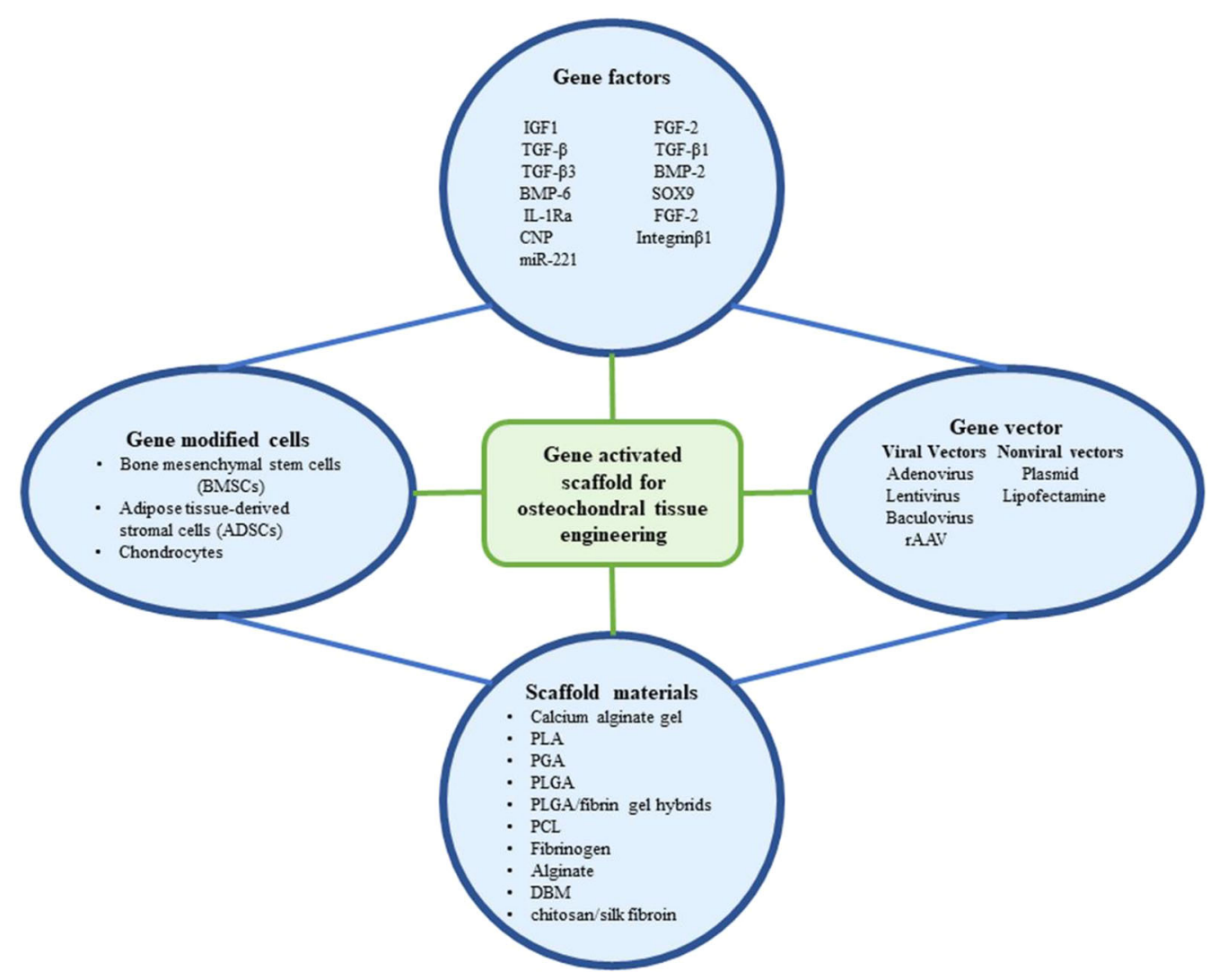

FIGURE 2 | The components that have been utilized in gene activated scaffold for osteochondral tissue engineering.

biodegradable poly-L-lysine coated polylactic acid (PLA) scaffolds which were transplanted into New Zealand rabbit articular cartilage full-thickness defects. In vitro, after 2 weeks of cell seeding, the cartilage matrix formed and filled with the attachment holes of the scaffold. In vivo, 24 weeks after transplantation, the hyaline cartilage repaired the cartilage defect area, trabecular bone and dense bone repair in the subchondral area and the quality of the regenerated tissue improved over time (Guo et al., 2006). Similarly, BMSCs were transduced with pDNATGF- $\beta 1$ and loaded into PLGA/fibrin gel hybrids which were implanted into rabbit articular cartilage models, resulting in the regeneration of new cartilage tissue with similar thickness, cell arrangements, color, and abundant glycosaminoglycans to normal cartilage (Li et al., 2014). Moreover, TGF- $\beta 1$-gene engineered rat BMSCs induced cartilage regeneration in rats (He et al., 2012), and their transfer onto PGA scaffolds using adenoviral approaches induced chondrogenic differentiation both in vitro and in vivo (Xia et al., 2009). Robust collagen II staining was observed in adenovirus-mediated-BMP- 2 and TGF- $\beta 3$ infected cells. DBM compounds with BMP- 2 and TGF- $\beta 3$ infected BMSC scaffolds showed high biocompatibility and the capacity to regeneration cartilage in pig models (Wang et al., 2014).

SOX9 is a transcription factor of the SOX (Sry-type HMG box) protein family that promotes cartilage formation and the phenotypes of chondrocytes. Adenoviral vectors have been used to transfect SOX9 into rabbit BMSCs which effectively induced their differentiation into chondrocytes on PGA scaffolds and improved the repair of cartilage defects (Cao et al., 2011). More recently, Venkatesan et al. designed 3D fibrin-polyurethane scaffolds in a hydrodynamic environment that provided a favorable growth environment for rAAV-infected SOX9modified hBMCs and promoted their differentiation into chondrocytes. Interestingly, the expression of SOX9 lasted 21 days, the longest time point evaluated (Venkatesan et al., 2018).

Cartilage engineering can also be mediated through gene activation matrices. Rowland et al. engineered lentiviral particles expressing a doxycycline-inducible IL-1 receptor antagonist (IL-1Ra) on a cartilage-derived matrix to prevent IL-1 mediated inflammation. Similar scaffolds have been employed for site directed chondrogenic and osteogenic differentiation using BMSC populations that overexpress either chondrogenic, BMP2, or TGF- $\beta 3$ transgenes. The ability to regulate IL-1Ra expression afforded protection to the cartilagematrix in the presence of IL-1, leading to enhanced bone production and cartilage formation. When inflammation is absent, cartilage-derived matrix hemispheres expressing TGF$\beta 3$ and BMP-2 were also fused to the bilayers of osteochondral constructs to promote healing (Rowland et al., 2018). Yang and 
coworkers also transfected BMSCs with adenoviruses expressing C-type natriuretic peptides and seeded the cells onto silk/ chitosan scaffolds to promote chondrogenesis in rat cartilage defect models (Yang et al., 2019).

Despite advances in the development of osteochondral repair scaffolds, their combination with miRNAs remains in the early stages. MiR-221 can induce BMSCs toward chondrogenesis in the absence of TGF- $\beta$ and could repair osteochondral defects following its subcutaneous implantation into mouse models, promoting Collagen type II positive tissue expression that was negative for collagen type X (a well characterized marker of hypertrophy). The potential of hMSCs silenced for miR-221 to suppress collagen type $\mathrm{X}$ represents an exciting development with clear therapeutic potential for cartilage repair in the clinic (Lolli et al., 2016).

\section{Gene Modified ADSCs}

It is now well accepted that ADSCs have clinical utility. An advantage is their ability to be collected via lipoaspiration, a noninvasive harvesting process. Lu and coworkers developed baculoviruses for FLPo/Frt expression of genetically engineered rabbit ADSCs. The cells were transfected with TGF- $\beta 3 /$ BMP-6 and added to PLGA-GCH scaffolds for implantation to cartilage defects in weight-bearing areas, promoting regeneration. The designed neo-cartilages had defined cartilage-specific-structures in the absence of degeneration or hypertrophy (Lu et al., 2014). In other studies, the inguinal fat of rats were transduced with SOX via retroviral approaches and ADSCs were collected and seeded into fibrin gels and implanted onto defects in the femur patellar groove. These approaches significantly increased type II collagen expression, GAG levels, and improved cartilage healing (Lee and Im, 2012). Upon seeding the ADSCs into large PCLscaffolds immobilized with Dox-inducible lentiviruses expressing IL-1Ra, controlled tissue growth and biomimetic cartilage properties were maintained (Moutos et al., 2016).

\section{Gene Modified Chondrocytes}

Isolated cartilage cells can be obtained through enzymatic digestion and can embed into cartilage lacuna, preventing immune cell invasion and organ rejection. However, the cells dedifferentiate overtime and their propensity for cartilage production becomes impaired, limiting their use in clinical application. The use of $3 \mathrm{D}$ cultures can mimic the microenvironment of the extracellular matrix permitting the maintenance of phenotypic stability. In this regard, neonatal male foals chondrocytes transduced with IGF-1-adenoviruses and embedded into fibrinogen were implanted into equine defects and conferred high levels of IGF-1 expression and cartilage healing (Goodrich et al., 2007). Griffin and colleagues used a comparable approach with rAAV5 and implanted the carriers into equine femurs, also showing improved graft healing (Griffin et al., 2016). FGF-2 and IGF-I plasmid vectors have also been delivered into Lapine articular chondrocytes. The cells were encapsulated into alginate scaffolds and transplanted onto rabbit knee joint defects for a period of three weeks, in which enhanced IGF-I/FGF-2 levels improved the defects with no adverse effects to the synovial membrane, highlighting the utility of these approaches to promote cartilage repair (Orth et al., 2011).

FGF-2 is mitogenic in articular chondrocytes and when transfected into articular chondrocytes and encapsulated in alginate scaffolds, FGF-2 expression was maintained for over 21 days and improved cartilage defects in the knee joints of rabbits. No adverse effects were again evident in the synovial membrane following histological assessments but type II collagen expression was enhanced (Kaul et al., 2006).

Mechanical movements activate integrin $\beta 1$-signaling and enhance the proliferative capacity of chondrocytes, increasing matrix synthesis. Liang and co-workers seeded integrin $\beta 1$ transfected chondrocytes onto PLGA scaffolds which produced higher levels of GAG and type II collagen after lentiviral-integrin $\beta 1$ transfection compared to mechanically stressed sham controls. The opposing phenotype was observed in the cells silenced for integrin $\beta 1$, suggesting that in addition to mechanical stimulation, the overexpression of integrin $\beta 1$ enhances cartilage regeneration (Liang et al., 2015) (Table 3).

\section{CONCLUSION AND FUTURE DIRECTIONS}

In summary, osteochondral defects are not a single cartilage or bone injury, but involve complex multi-structural components. The healing of these components is challenging. To-date, there is no technology that can form a natural cartilage structures in the joints. Osteochondral tissue engineering shows good potential for osteochondral repair and OA treatment, but several problems remain. For example, at the seed cell level, chondrocytes have poor availability and dedifferentiation properties. Unacceptable outcomes such as chondrocyte hypertrophy and endochondral ossification are often accompanied by an inability to control the differentiation of chondrogenic SCs. Also, due to its unique layered structure, osteochondral tissue theoretically requires a multi-phase structure to simulate the native layered structure, but this is difficult to achieve. Recent studies have shown that a combination of gene vectors, genes, seed cells, and scaffolds are more likely to obtain hyaline cartilage, with the combined changes between them primarily based on lesion size, location, and structure.

Genes have been transfected into MSCs or chondrocytes to improve their phenotypic properties. In general, cartilage gene therapy enables seed cells to continuously encode growth factors, transcription factors, or anti-inflammatory cytokines, thereby inducing cartilage differentiation and inhibiting the progression of inflammatory diseases (Figure 2). Studies have shown that multiple combinations of genes encoding growth factors, transcription factors, or anti-adverse response cytokines are more advantageous than single genes for improving healing and reducing adverse effects. To minimize hypertrophy, ossification, and host immune responses, complex gene delivery vectors must be designed to increase safety and more sustained gene protein release. miRNAs regulate chondrogenesis and arthritis. The expression of a specific miRNA mimetic or miRNA inhibitor permits the manipulation of the expression profiles of the cellular miRNAs and their epigenetic features. On this basis, combined 
TABLE 3 | Summary of gene therapy in scaffold based osteochondral tissue repair.

\begin{tabular}{|c|c|c|c|c|c|c|}
\hline Cells & Gene & Scaffold & Gene vector & Approach & Vitro or vivo model & Reference \\
\hline \multirow[t]{10}{*}{ BMSCs } & IGF1 & Calcium alginate gel & Plasmid & Ex vivo & Rabbit knee osteochondral defect & (Leng et al., 2012) \\
\hline & TGF- $\beta$ & PLA & Plasmid & Ex vivo & Rabbit knee full-thickness defects & (Guo et al., 2006) \\
\hline & TGF- $\beta 1$ & PLGA/fibrin gel hybrids & Plasmid & Ex vivo & Rabbit knee full-thickness defects & (Li et al., 2014) \\
\hline & TGF- $\beta 1$ & PGA & Adenovirus & In vitro, ex vivo & Mice subcutaneous tissue & (Xia et al., 2009) \\
\hline & BMP-2, TGF- $\beta 3$ & DBM & Adenovirus & In vitro, ex vivo & Pig knee full-thickness defects & (Wang et al., 2014) \\
\hline & SOX9 & PGA & Adenovirus & In vitro, ex vivo & Rabbit knee full-thickness defects & (Cao et al., 2011) \\
\hline & SOX9 & Fibrin-polyurethane & rAAV & In vitro & Hydrodynamic culture conditions & (Venkatesan et al., 2018 \\
\hline & $\begin{array}{l}\text { IL-1Ra, BMP-2, } \\
\text { TGF- } \beta 3\end{array}$ & CDM & Lentiviral & In vitro & Joint organoid model & (Rowland et al., 2018) \\
\hline & CNP & Chitosan/silk fibroin & Adenovirus & Ex vivo & Rat knee full-thickness defects & (Yang et al., 2019) \\
\hline & $\operatorname{miR}-221$ & Alginate & Lipofectamine & In vitro, ex vivo & Mice knee osteochondral defects & (Lolli et al., 2016) \\
\hline \multirow[t]{3}{*}{ ADSCs } & TGF- $\beta 3 / B M P-6$ & PLGA-GCH & Baculovirus & Ex vivo & Rat knee full-thickness defects & (Lu et al., 2014) \\
\hline & SOX trio & Fibrin gel & Retrovirus & In vitro, ex vivo & Rat knee osteochondral defect, OA & (Lee and Im, 2012) \\
\hline & eGFP, IL-1Ra & $\mathrm{PCL}$ & Lentiviral & In vitro & Cultured in chondrogenic conditions & (Moutos et al., 2016) \\
\hline \multirow[t]{5}{*}{ Chondrocytes } & IGF-1 & Fibrinogen & Adenovirus & Ex vivo & Equine knee osteochondral defect & (Goodrich et al., 2007) \\
\hline & IGF-1 & Fibrin & rAAV5 & Ex vivo & Equine knee full-thickness defects & (Griffin et al., 2016) \\
\hline & IGF-I, FGF-2 & Alginate & Plasmid & Ex vivo & Rabbit knee osteochondral defect & (Orth et al., 2011) \\
\hline & FGF-2 & Alginate & Plasmid & In vitro, ex vivo & Rabbit knee osteochondral defect & (Kaul et al., 2006) \\
\hline & Integrin $\beta 1$ & PLGA & Lentiviral & In vitro & $\begin{array}{l}\text { Cultured under periodic } \\
\text { mechanical stress }\end{array}$ & (Liang et al., 2015) \\
\hline
\end{tabular}

IGF, Insulin-like growth factor; TGF, Transforming growth factor; BMP, Bone morphogenetic protein; PLGA, Poly lactide-co-glycolide; DBM, Demineralized bone matrix; PGA, polyglycolic; GCH, gelatin, chondroitin-6-sulfate and hyaluronic acid; IL-1Ra, IL-1 receptor antagonist; eGFP, enhanced green fluorescent protein.

with 3D biological scaffold printing technology, it is more conducive to accurately control cell differentiation and optimize the biochemical and biomechanical properties of regenerated tissues. However, the use of 3D delivery systems to miRNAactivated scaffolds is in its infancy. Moreover, in terms of scaffolds, 3D multiphase structural scaffolds are complex, and not conducive to the control of each phase, including degradation rates and shear forces. Therefore, the two-phase scaffold divided into a cartilage phase and a bone phase is simpler than multi-phase scaffolds and ideal for osteochondral scaffolds (Seo et al., 2014). We propose that to make full use of the integrated fusion bilayer scaffold, each genetically modified cell line (overexpression or knockout of miRNA) can edit specific signaling molecules that facilitate tissue regeneration in each layer.

\section{REFERENCES}

Aho, O. M., Finnila, M., Thevenot, J., Saarakkala, S., and Lehenkari, P. (2017). Subchondral bone histology and grading in osteoarthritis. PloS One 12 (3), e0173726. doi: 10.1371/journal.pone.0173726

Anderson, B. A., and McAlinden, A. (2017). miR-483 targets SMAD4 to suppress chondrogenic differentiation of human mesenchymal stem cells. J. Orthop. Res. 35 (11), 2369-2377. doi: 10.1002/jor.23552

Antonova, L. V., Seifalian, A. M., Kutikhin, A. G., Sevostyanova, V. V., Krivkina, E. O., Mironov, A. V., et al. (2016). Bioabsorbable bypass grafts biofunctionalised with RGD have enhanced biophysical properties and endothelialisation tested in vivo. Front. Pharmacol. 7, 136. doi: 10.3389/fphar.2016.00136

Arfat, Y., Basra, M. A. R., Shahzad, M., Majeed, K., Mahmood, N., and Munir, H. (2018). miR-208a-3p suppresses osteoblast differentiation and inhibits bone formation by targeting ACVR1. Mol. Ther. Nucleic Acids 11, 323-336. doi: 10.1016/j.omtn.2017.11.009

Armiento, A. R., Alini, M., and Stoddart, M. J. (2018). Articular fibrocartilagewhy does hyaline cartilage fail to repair? Adv. Drug Deliv. Rev. 146, 289-305. doi: 10.1016/j.addr.2018.12.015

Asgharzadeh, A., Alizadeh, S., Keramati, M. R., Soleimani, M., Atashi, A., Edalati, M., et al. (2018). Upregulation of miR-210 promotes differentiation of mesenchymal

\section{AUTHOR CONTRIBUTIONS}

$\mathrm{XY}, \mathrm{Y}-\mathrm{RC}$, and Y-FS proposed and wrote the manuscript. MY, JY, and GZ collected and analyzed the information. J-KY supervised the conception and writing of the manuscript.

\section{FUNDING}

The research was supported by the National Natural Science Foundation of China (Grant Nos. 51773004, 81630056, 51920105006, 51803188, 31670982) and the National Key Research and Development Program (Grant No. 2016YFC1100704).

stem cells (MSCs) into osteoblasts. Bosn. J. Basic Med. Sci. 18 (4), 328-335. doi: 10.17305/bjbms.2018.2633

Bai, M., Yin, H., Zhao, J., Li, Y., and Wu, Y. (2019). miR-182-5p overexpression inhibits chondrogenesis by down-regulating PTHLH. Cell Biol. Int. 43 (3), 222-232. doi: 10.1002/cbin.11047

Bluhm, B., Ehlen, H. W. A., Holzer, T., Georgieva, V. S., Heilig, J., Pitzler, L., et al. (2017). miR-322 stabilizes MEK1 expression to inhibit RAF/MEK/ERK pathway activation in cartilage. Development 144 (19), 3562-3577. doi: 10.1242/dev.148429

Brunger, J. M., Huynh, N. P., Guenther, C. M., Perez-Pinera, P., Moutos, F. T., Sanchez-Adams, J., et al. (2014). Scaffold-mediated lentiviral transduction for functional tissue engineering of cartilage. Proc. Natl. Acad. Sci. U.S.A. 111 (9), E798-E806. doi: 10.1073/pnas.1321744111

Budd, E., de Andres, M. C., Sanchez-Elsner, T., and Oreffo, R. O. C. (2017). MiR$146 \mathrm{~b}$ is down-regulated during the chondrogenic differentiation of human bone marrow derived skeletal stem cells and up-regulated in osteoarthritis. Sci. Rep. 7, 46704. doi: 10.1038/srep46704

Cai, C., Min, S., Yan, B., Liu, W., Yang, X., Li, L., et al. (2019). MiR-27a promotes the autophagy and apoptosis of IL-1beta treated-articular chondrocytes in osteoarthritis through PI3K/AKT/mTOR signaling. Aging (Albany NY) 11 (16), 6371-6384. doi: 10.18632/aging.102194 
Camp, E., Pribadi, C., Anderson, P. J., Zannettino, A. C. W., and Gronthos, S. (2018). miRNA-376c-3p mediates TWIST-1 inhibition of bone marrowderived stromal cell osteogenesis and can reduce aberrant bone formation of TWIST-1 haploinsufficient calvarial cells. Stem Cells Dev. 27 (23), 1621-1633. doi: $10.1089 /$ scd.2018.0083

Cao, L., Yang, F., Liu, G., Yu, D., Li, H., Fan, Q., et al. (2011). The promotion of cartilage defect repair using adenovirus mediated Sox9 gene transfer of rabbit bone marrow mesenchymal stem cells. Biomaterials 32 (16), 3910-3920. doi: 10.1016/j.biomaterials.2011.02.014

Celik, E., Bayram, C., and Denkbas, E. B. (2019). Chondrogenesis of human mesenchymal stem cells by microRNA loaded triple polysaccharide nanoparticle system. Mater. Sci. Eng. C. Mater. Biol. Appl. 102, 756-763. doi: 10.1016/j.msec.2019.05.006

Chen, J., and Wu, X. (2019). Cyclic tensile strain promotes chondrogenesis of bone marrow-derived mesenchymal stem cells by increasing miR-365 expression. Life Sci. 232, 116625. doi: 10.1016/j.lfs.2019.116625

Chen, C. L., Luo, W. Y., Lo, W. H., Lin, K. J., Sung, L. Y., Shih, Y. S., et al. (2011). Development of hybrid baculovirus vectors for artificial MicroRNA delivery and prolonged gene suppression. Biotechnol. Bioeng. 108 (12), 2958-2967. doi: 10.1002/bit.23250

Chen, Y., Wang, X., Yang, M., Ruan, W., Wei, W., Gu, D., et al. (2018). miR-145$5 \mathrm{p}$ increases osteoclast numbers in vitro and aggravates bone erosion in collagen-induced arthritis by targeting osteoprotegerin. Med. Sci. Monit. 24, 5292-5300. doi: 10.12659/MSM.908219

Chen, H., Yang, J., and Tan, Z. (2019a). Upregulation of microRNA-9-5p inhibits apoptosis of chondrocytes through downregulating Tnc in mice with osteoarthritis following tibial plateau fracture. J. Cell Physiol. 234 (12), 23326-23336. doi: 10.1002/jcp.28900

Chen, J., He, G., Wang, Y., and Cai, D. (2019b). MicroRNA223 promotes osteoblast differentiation of MC3T3E1 cells by targeting histone deacetylase 2. Int. J. Mol. Med. 43 (3), 1513-1521. doi: 10.3892/ijmm.2018.4042

Chen, S., Xu, Z., Shao, J., Fu, P., and Wu, H. (2019c). MicroRNA-218 promotes early chondrogenesis of mesenchymal stem cells and inhibits later chondrocyte maturation. BMC Biotechnol. 19 (1), 6. doi: 10.1186/s12896-018-0496-0

Chen, Y., Yang, Y. R., Fan, X. L., Lin, P., Yang, H., Chen, X. Z., et al. (2019d). miR206 inhibits osteogenic differentiation of bone marrow mesenchymal stem cells by targetting glutaminase. Biosci. Rep. 39 (3), BSR20181108. doi: 10.1042/ BSR20181108

Chen, Z., Wang, Z., and Gu, Z. (2019e). Bioinspired and biomimetic nanomedicines. Acc. Chem. Res. 52 (5), 1255-1264. doi: 10.1021/ acs.accounts.9b00079

Cong, F., Wu, N., Tian, X., Fan, J., Liu, J., Song, T., et al. (2017a). MicroRNA-34c promotes osteoclast differentiation through targeting LGR4. Gene 610, 1-8. doi: 10.1016/j.gene.2017.01.028

Cong, L., Zhu, Y., and Tu, G. (2017b). A bioinformatic analysis of microRNAs role in osteoarthritis. Osteoarthr. Cartil. 25 (8), 1362-1371. doi: 10.1016/ j.joca.2017.03.012

Ding, Y., Wang, L., Zhao, Q., Wu, Z., and Kong, L. (2019). MicroRNA93 inhibits chondrocyte apoptosis and inflammation in osteoarthritis by targeting the TLR4/NFkappaB signaling pathway. Int. J. Mol. Med. 43 (2), 779-790. doi: 10.3892/ijmm.2018.4033

Duan, L., Zhao, H., Xiong, Y., Tang, X., Yang, Y., Hu, Z., et al. (2018). miR-16-2* interferes with WNT5A to regulate osteogenesis of mesenchymal stem cells. Cell Physiol. Biochem. 51 (3), 1087-1102. doi: 10.1159/000495489

Franses, R. E., McWilliams, D. F., Mapp, P. I., and Walsh, D. A. (2010). Osteochondral angiogenesis and increased protease inhibitor expression in OA. Osteoarthr. Cartil. 18 (4), 563-571. doi: 10.1016/j.joca.2009.11.015

Fu, T. S., Chang, Y. H., Wong, C. B., Wang, I. C., Tsai, T. T., Lai, P. L., et al. (2015). Mesenchymal stem cells expressing baculovirus-engineered BMP-2 and VEGF enhance posterolateral spine fusion in a rabbit model. Spine J. 15 (9), 20362044. doi: 10.1016/j.spinee.2014.11.002

Gabisonia, K., Prosdocimo, G., Aquaro, G. D., Carlucci, L., Zentilin, L., Secco, I., et al. (2019). MicroRNA therapy stimulates uncontrolled cardiac repair after myocardial infarction in pigs. Nature 569 (7756), 418-422. doi: 10.1038/ s41586-019-1191-6

Ginn, S. L., Amaya, A. K., Alexander, I. E., Edelstein, M., and Abedi, M. R. (2018). Gene therapy clinical trials worldwide to 2017: an update. J. Gene Med. 20 (5), e3015. doi: 10.1002/jgm.3015
Goodrich, L. R., Hidaka, C., Robbins, P. D., Evans, C. H., and Nixon, A. J. (2007). Genetic modification of chondrocytes with insulin-like growth factor-1 enhances cartilage healing in an equine model. J. Bone Joint Surg. Br. 89 (5), 672-685. doi: 10.1302/0301-620X.89B5.18343

Griffin, D. J., Ortved, K. F., Nixon, A. J., and Bonassar, L. J. (2016). Mechanical properties and structure-function relationships in articular cartilage repaired using IGF-I gene-enhanced chondrocytes. J. Orthop. Res. 34 (1), 149-153. doi: 10.1002/jor.23038

Guo, X., Zheng, Q., Yang, S., Shao, Z., Yuan, Q., Pan, Z., et al. (2006). Repair of full-thickness articular cartilage defects by cultured mesenchymal stem cells transfected with the transforming growth factor betal gene. Biomed. Mater. 1 (4), 206-215. doi: 10.1088/1748-6041/1/4/006

Guo, K., Zhang, D., Wu, H., Zhu, Q., Yang, C., and Zhu, J. (2018). MiRNA-199a$5 \mathrm{p}$ positively regulated RANKL-induced osteoclast differentiation by target Mafb protein. J. Cell Biochem. 120 (5), 7024-7031. doi: 10.1002/jcb.27968

Guo, J., Zeng, X., Miao, J., Liu, C., Wei, F., Liu, D., et al. (2019a). MiRNA-218 regulates osteoclast differentiation and inflammation response in periodontitis rats through Mmp9. Cell Microbiol. 21 (4), e12979. doi: 10.1111/cmi.12979

Guo, P. Y., Wu, L. F., Xiao, Z. Y., Huang, T. L., and Li, X. (2019b). Knockdown of MiR-140-5 promotes osteogenesis of adipose-derived mesenchymal stem cells by targeting TLR4 and BMP2 and promoting fracture healing in the atrophic nonunion rat model. Eur. Rev. Med. Pharmacol. Sci. 23 (5), 2112-2124. doi: 10.26355/eurrev_201903_17255

Han, Y., Zhang, K., Hong, Y., Wang, J., Liu, Q., Zhang, Z., et al. (2018). miR-3423 p promotes osteogenic differentiation via targeting ATF3. FEBS Lett. 592 (24), 4051-4065. doi: 10.1002/1873-3468.13282

He, C. X., Zhang, T. Y., Miao, P. H., Hu, Z. J., Han, M., Tabata, Y., et al. (2012). TGF-betal gene-engineered mesenchymal stem cells induce rat cartilage regeneration using nonviral gene vector. Biotechnol. Appl. Biochem. 59 (3), 163-169. doi: 10.1002/bab.1001

He, G., Chen, J., and Huang, D. (2019). miR-877-3p promotes TGF-betal-induced osteoblast differentiation of MC3T3-E1 cells by targeting Smad7. Exp. Ther. Med. 18 (1), 312-319. doi: 10.3892/etm.2019.7570

Hoseinzadeh, S., Atashi, A., Soleimani, M., Alizadeh, E., and Zarghami, N. (2016) MiR-221-inhibited adipose tissue-derived mesenchymal stem cells bioengineered in a nano-hydroxy apatite scaffold. In Vitro Cell Dev. Biol. Anim. 52 (4), 479-487. doi: 10.1007/s11626-015-9992-x

Hrdlicka, H. C., Lee, S. K., and Delany, A. M. (2019). MicroRNAs are critical regulators of osteoclast differentiation. Curr. Mol. Biol. Rep. 5 (1), 65-74. doi: 10.1007/s40610-019-0116-3

Hsu, F. Y., Hung, Y. S., Liou, H. M., and Shen, C. H. (2010). Electrospun hyaluronate-collagen nanofibrous matrix and the effects of varying the concentration of hyaluronate on the characteristics of foreskin fibroblast cells. Acta Biomater. 6 (6), 2140-2147. doi: 10.1016/j.actbio.2009.12.023

Hu, W., Zhang, W., Li, F., Guo, F., and Chen, A. (2016). miR-139 is up-regulated in osteoarthritis and inhibits chondrocyte proliferation and migration possibly via suppressing EIF4G2 and IGF1R. Biochem. Biophys. Res. Commun. 474 (2), 296-302. doi: 10.1016/j.bbrc.2016.03.164

Hu, G., Zhao, X., Wang, C., Geng, Y., Zhao, J., Xu, J., et al. (2017). MicroRNA-145 attenuates TNF-alpha-driven cartilage matrix degradation in osteoarthritis via direct suppression of MKK4. Cell Death Dis. 8 (10), e3140. doi: 10.1038/ cddis.2017.522

Hu, S., Mao, G., Zhang, Z., Wu, P., Wen, X., Liao, W., et al. (2019). MicroRNA$320 \mathrm{c}$ inhibits development of osteoarthritis through downregulation of canonical Wnt signaling pathway. Life Sci. 228, 242-250. doi: 10.1016/ j.lfs.2019.05.011

Jia, H. L., and Zhou, D. S. (2018). Downregulation of microRNA-367 promotes osteoblasts growth and proliferation of mice during fracture by activating the PANX3-mediated Wnt/beta-catenin pathway. J. Cell Biochem. 120 (5), 8247 8258. doi: $10.1002 /$ jcb. 28108

Jia, D., Li, Y., Han, R., Wang, K., Cai, G., He, C., et al. (2019). miR146a5p expression is upregulated by the CXCR4 antagonist TN14003 and attenuates SDFlinduced cartilage degradation. Mol. Med. Rep. 19 (5), 4388-4400. doi: 10.3892/mmr.2019.10076

Jin, Y., Hong, F., Bao, Q., Xu, Q., Duan, R., Zhu, Z., et al. (2019). MicroRNA-145 suppresses osteogenic differentiation of human jaw bone marrow mesenchymal stem cells partially via targeting semaphorin 3A. Connect Tissue Res., 1-9. doi: 10.1080/03008207.2019.1643334 
John, A. A., Prakash, R., and Singh, D. (2019). miR-487b-3p impairs osteoblastogenesis by targeting Notch-regulated ankyrin-repeat protein (Nrarp). J. Endocrinol. 241 (3), 249-263. doi: 10.1530/JOE-19-0015

Kaul, G., Cucchiarini, M., Arntzen, D., Zurakowski, D., Menger, M. D., Kohn, D., et al. (2006). Local stimulation of articular cartilage repair by transplantation of encapsulated chondrocytes overexpressing human fibroblast growth factor 2 (FGF-2) in vivo. J. Gene Med. 8 (1), 100-111. doi: 10.1002/jgm.819

Klinger, P., Surmann-Schmitt, C., Brem, M., Swoboda, B., Distler, J. H., Carl, H. D., et al. (2011). Chondromodulin 1 stabilizes the chondrocyte phenotype and inhibits endochondral ossification of porcine cartilage repair tissue. Arthritis Rheumatol. 63 (9), 2721-2731. doi: 10.1002/art.30335

Kou, J., Zheng, X., Guo, J., Liu, Y., and Liu, X. (2019). MicroRNA-218-5p relieves postmenopausal osteoporosis through promoting the osteoblast differentiation of bone marrow mesenchymal stem cells. J. Cell Biochem. 121 (2), 1216-1226. doi: $10.1002 /$ jcb. 29355

Kowalczewski, C. J., and Saul, J. M. (2018). Biomaterials for the delivery of growth factors and other therapeutic agents in tissue engineering approaches to bone regeneration. Front. Pharmacol. 9, 513. doi: 10.3389/fphar.2018.00513

Lee, J. M., and Im, G. I. (2012). SOX trio-co-transduced adipose stem cells in fibrin gel to enhance cartilage repair and delay the progression of osteoarthritis in the rat. Biomaterials 33 (7), 2016-2024. doi: 10.1016/ j.biomaterials.2011.11.050

Leng, P., Ding, C. R., Zhang, H. N., and Wang, Y. Z. (2012). Reconstruct large osteochondral defects of the knee with hIGF-1 gene enhanced mosaicplasty. Knee 19 (6), 804-811. doi: 10.1016/j.knee.2012.03.009

Li, L., and Jiang, D. (2019). Hypoxia-responsive miRNA-21-5p inhibits Runx2 suppression by targeting SMAD7 in MC3T3-E1 cells. J. Cell Biochem. 120 (10), 16867-16875. doi: 10.1002/jcb.28944

Li, B., Li, F., Ma, L., Yang, J., Wang, C., Wang, D., et al. (2014). Poly(lactide-coglycolide)/fibrin gel construct as a $3 \mathrm{D}$ model to evaluate gene therapy of cartilage in vivo. Mol. Pharm. 11 (7), 2062-2070. doi: 10.1021/mp5000136

Li, L., Jia, J., Liu, X., Yang, S., Ye, S., Yang, W., et al. (2015). MicroRNA-16-5p controls development of osteoarthritis by targeting SMAD3 in chondrocytes. Curr. Pharm. Des. 21 (35), 5160-5167. doi: 10.2174/1381612821666150909094712

Li, X., Ding, J., Zhang, Z., Yang, M., Yu, J., Wang, J., et al. (2016). Kartogeninincorporated thermogel supports stem cells for significant cartilage regeneration. ACS Appl. Mater. Interfaces 8 (8), 5148-5159. doi: 10.1021/ acsami.5b12212

Li, X., He, P., Li, Z., Wang, H., Liu, M., Xiao, Y., et al. (2018a). Interleukin1 beta mediated suppression of microRNA27a3p activity in human cartilage via MAPK and NFkappaB pathways: a potential mechanism of osteoarthritis pathogenesis. Mol. Med. Rep. 18 (1), 541-549. doi: 10.3892/mmr.2018.8970

Li, Z., Zhang, W., and Huang, Y. (2018b). MiRNA-133a is involved in the regulation of postmenopausal osteoporosis through promoting osteoclast differentiation. Acta Biochim. Biophys. Sin. (Shanghai) 50 (3), 273-280. doi: 10.1093/abbs/gmy006

Li, M., Luo, R., Yang, W., Zhou, Z., and Li, C. (2019a). miR-363-3p is activated by MYB and regulates osteoporosis pathogenesis via PTEN/PI3K/AKT signaling pathway. In Vitro Cell Dev. Biol. Anim. 55 (5), 376-386. doi: 10.1007/s11626019-00344-5

Li, W., Wang, X., Chang, L., and Wang, F. (2019b). MiR-377 inhibits wear particle-induced osteolysis via targeting RANKL. Cell Biol. Int. 43 (6), 658-668. doi: $10.1002 /$ cbin. 11143

Li, W., Zhao, S., Yang, H., Zhang, C., Kang, Q., Deng, J., et al. (2019c). Potential novel prediction of TMJ-OA: MiR-140-5p regulates inflammation through Smad/TGF-beta signaling. Front. Pharmacol. 10, 15. doi: 10.3389/ fphar.2019.00015

Li, Y., Feng, C., Gao, M., Jin, M., Liu, T., Yuan, Y., et al. (2019d). MicroRNA-92b$5 \mathrm{p}$ modulates melatonin-mediated osteogenic differentiation of bone marrow mesenchymal stem cells by targeting ICAM-1. J. Cell Mol. Med. 23 (9), 61406153. doi: $10.1111 / \mathrm{jcmm} .14490$

Liang, W., Zhu, C., Liu, F., Cui, W., Wang, Q., Chen, Z., et al. (2015). Integrin betal gene therapy enhances in vitro creation of tissue-engineered cartilage under periodic mechanical stress. Cell Physiol. Biochem. 37 (4), 1301-1314. doi: $10.1159 / 000430253$

Lima, A. C., Ferreira, H., Reis, R. L., and Neves, N. M. (2019). Biodegradable polymers: an update on drug delivery in bone and cartilage diseases. Expert. Opin. Drug Deliv. 16 (8), 795-813. doi: 10.1080/17425247.2019.1635117
Lin, J. C., Liu, Z. G., Yu, B., and Zhang, X. R. (2018). MicroRNA-874 targeting SUFU involves in osteoblast proliferation and differentiation in osteoporosis rats through the Hedgehog signaling pathway. Biochem. Biophys. Res. Commun. 506 (1), 194-203. doi: 10.1016/j.bbrc.2018.09.187

Lin, S. S., Yuan, L. J., Niu, C. C., Tu, Y. K., Yang, C. Y., and Ueng, S. W. N. (2019). Hyperbaric oxygen inhibits the HMGB1/RAGE signaling pathway by upregulating Mir-107 expression in human osteoarthritic chondrocytes. Osteoarthr. Cartil. 27 (9), 1372-1381. doi: 10.1016/j.joca.2019.05.011

Liu, H., Cheng, Y., Chen, J., Chang, F., Wang, J., Ding, J., et al. (2018). Component effect of stem cell-loaded thermosensitive polypeptide hydrogels on cartilage repair. Acta Biomater. 73, 103-111. doi: 10.1016/j.actbio.2018.04.035

Liu, M., Sun, F., Feng, Y., Sun, X., Li, J., Fan, Q., et al. (2019a). MicroRNA-132-3p represses Smad5 in MC3T3-E1 osteoblastic cells under cyclic tensile stress. Mol. Cell Biochem. 458 (1-2), 143-157. doi: 10.1007/s11010-019-03538-3

Liu, X., Liu, L., Zhang, H., Shao, Y., Chen, Z., Feng, X., et al. (2019b). MiR-146b accelerates osteoarthritis progression by targeting alpha-2-macroglobulin. Aging (Albany NY) 11 (16), 6014-6028. doi: 10.18632/aging.102160

Lo, S. C., Li, K. C., Chang, Y. H., Hsu, M. N., Sung, L. Y., Vu, T. A., et al. (2017). Enhanced critical-size calvarial bone healing by ASCs engineered with Cre/ loxP-based hybrid baculovirus. Biomaterials 124, 1-11. doi: 10.1016/ j.biomaterials.2017.01.033

Lolli, A., Narcisi, R., Lambertini, E., Penolazzi, L., Angelozzi, M., Kops, N., et al. (2016). Silencing of antichondrogenic microRNA-221 in human mesenchymal stem cells promotes cartilage repair in vivo. Stem Cells 34 (7), 1801-1811. doi: $10.1002 /$ stem.2350

Lou, Z., Peng, Z., Wang, B., Li, X., Li, X., and Zhang, X. (2019). miR-142-5p promotes the osteoclast differentiation of bone marrow-derived macrophages via PTEN/PI3K/AKT/FoxO1 pathway. J. Bone Miner. Metab. 37 (5), 815-824. doi: 10.1007/s00774-019-00997-y

Lu, C. H., Yeh, T. S., Yeh, C. L., Fang, Y. H., Sung, L. Y., Lin, S. Y., et al. (2014). Regenerating cartilages by engineered ASCs: prolonged TGF-beta3/BMP-6 expression improved articular cartilage formation and restored zonal structure. Mol. Ther. 22 (1), 186-195. doi: 10.1038/mt.2013.165

Ma, S., Wang, D. D., Ma, C. Y., and Zhang, Y. D. (2019a). microRNA-96 promotes osteoblast differentiation and bone formation in ankylosing spondylitis mice through activating the Wnt signaling pathway by binding to SOST. J. Cell Biochem. 120 (9), 15429-15442. doi: 10.1002/jcb.28810

Ma, Y., Wu, Y., Chen, J., Huang, K., Ji, B., Chen, Z., et al. (2019b). miR-10a-5p promotes chondrocyte apoptosis in osteoarthritis by targeting HOXA1. Mol. Ther. Nucleic Acids 14, 398-409. doi: 10.1016/j.omtn.2018.12.012

Mao, G., Wu, P., Zhang, Z., Zhang, Z., Liao, W., Li, Y., et al. (2017a). MicroRNA$92 a-3 p$ regulates aggrecanase- 1 and aggrecanase- 2 expression in chondrogenesis and IL-1beta-induced catabolism in human articular chondrocytes. Cell Physiol. Biochem. 44 (1), 38-52. doi: 10.1159/000484579

Mao, G., Zhang, Z., Huang, Z., Chen, W., Huang, G., Meng, F., et al. (2017b). MicroRNA-92a-3p regulates the expression of cartilage-specific genes by directly targeting histone deacetylase 2 in chondrogenesis and degradation. Osteoarthr. Cartil. 25 (4), 521-532. doi: 10.1016/j.joca.2016.11.006

Mao, G., Hu, S., Zhang, Z., Wu, P., Zhao, X., Lin, R., et al. (2018a). Exosomal miR-95-5p regulates chondrogenesis and cartilage degradation via histone deacetylase 2/8. J. Cell Mol. Med. 22 (11), 5354-5366. doi: 10.1111/ jcmm. 13808

Mao, G., Zhang, Z., Hu, S., Zhang, Z., Chang, Z., Huang, Z., et al. (2018b). Exosomes derived from miR-92a-3p-overexpressing human mesenchymal stem cells enhance chondrogenesis and suppress cartilage degradation via targeting WNT5A. Stem. Cell Res. Ther. 9 (1), 247. doi: 10.1186/s13287-0181004-0

McMillan, A., Nguyen, M. K., Gonzalez-Fernandez, T., Ge, P., Yu, X., Murphy, W. L., et al. (2018). Dual non-viral gene delivery from microparticles within 3D highdensity stem cell constructs for enhanced bone tissue engineering. Biomaterials 161, 240-255. doi: 10.1016/j.biomaterials.2018.01.006

Meng, F., Zhang, Z., Chen, W., Huang, G., He, A., Hou, C., et al. (2016). MicroRNA-320 regulates matrix metalloproteinase-13 expression in chondrogenesis and interleukin-lbeta-induced chondrocyte responses. Osteoarthr. Cartil. 24 (5), 932-941. doi: 10.1016/j.joca.2015.12.012

Meng, F., Li, Z., Zhang, Z., Yang, Z., Kang, Y., Zhao, X., et al. (2018). MicroRNA193b-3p regulates chondrogenesis and chondrocyte metabolism by targeting HDAC3. Theranostics 8 (10), 2862-2883. doi: 10.7150/thno.23547 
Mirzamohammadi, F., Papaioannou, G., and Kobayashi, T. (2014). MicroRNAs in cartilage development, homeostasis, and disease. Curr. Osteoporos. Rep. 12 (4), 410-419. doi: 10.1007/s11914-014-0229-9

Moutos, F. T., Glass, K. A., Compton, S. A., Ross, A. K., Gersbach, C. A., Guilak, F., et al. (2016). Anatomically shaped tissue-engineered cartilage with tunable and inducible anticytokine delivery for biological joint resurfacing. Proc. Natl. Acad. Sci. U. S. A. 113 (31), E4513-E4522. doi: 10.1073/pnas.1601639113

Niu, D., Gong, Z., Sun, X., Yuan, J., Zheng, T., Wang, X., et al. (2019). miR-338-3p regulates osteoclastogenesis via targeting IKKbeta gene. In Vitro Cell Dev. Biol. Anim. 55 (4), 243-251. doi: 10.1007/s11626-019-00325-8

Nooeaid, P., Salih, V., Beier, J. P., and Boccaccini, A. R. (2012). Osteochondral tissue engineering: scaffolds, stem cells and applications. J. Cell Mol. Med. 16 (10), 2247-2270. doi: 10.1111/j.1582-4934.2012.01571.x

Orth, P., Kaul, G., Cucchiarini, M., Zurakowski, D., Menger, M. D., Kohn, D., et al. (2011). Transplanted articular chondrocytes co-overexpressing IGF-I and FGF-2 stimulate cartilage repair in vivo. Knee Surg. Sports Traumatol. Arthrosc. 19 (12), 2119-2130. doi: 10.1007/s00167-011-1448-6

Pan, J., Huang, C., Chen, G., Cai, Z., and Zhang, Z. (2018). MicroRNA-451 blockade promotes osteoblastic differentiation and skeletal anabolic effects by promoting YWHAZ-mediated RUNX2 protein stabilization. Medchemcomm 9 (8), 1359-1368. doi: 10.1039/c8md00187a

Peng, W. X., and Wang, L. (2017). Adenovirus-mediated expression of BMP-2 and BFGF in bone marrow mesenchymal stem cells combined with demineralized bone matrix for repair of femoral head osteonecrosis in beagle dogs. Cell Physiol. Biochem. 43 (4), 1648-1662. doi: 10.1159/000484026

Press, T., Viale-Bouroncle, S., Felthaus, O., Gosau, M., and Morsczeck, C. (2015). EGR1 supports the osteogenic differentiation of dental stem cells. Int. Endod. J. 48 (2), 185-192. doi: 10.1111/iej.12299

Qin, W., Liu, L., Wang, Y., Wang, Z., Yang, A., and Wang, T. (2019). Mir-494 inhibits osteoblast differentiation by regulating BMP signaling in simulated microgravity. Endocrine 65 (2), 426-439. doi: 10.1007/s12020-019-01952-7

Raftery, R. M., Walsh, D. P., Blokpoel Ferreras, L., Mencia Castano, I., Chen, G., LeMoine, M., et al. (2019). Highly versatile cell-penetrating peptide loaded scaffold for efficient and localised gene delivery to multiple cell types: from development to application in tissue engineering. Biomaterials 216, 119277. doi: 10.1016/j.biomaterials.2019.119277

Reyes, R., Delgado, A., Sanchez, E., Fernandez, A., Hernandez, A., and Evora, C. (2014). Repair of an osteochondral defect by sustained delivery of BMP-2 or TGFbetal from a bilayered alginate-PLGA scaffold. J. Tissue Eng. Regener. Med. 8 (7), 521-533. doi: 10.1002/term.1549

Reziwan, K., Sun, D., Zhang, B., and Zhao, Z. (2019). MicroRNA-1225 activates Keap1-Nrf2-HO-1 signalling to inhibit TNFalpha-induced osteoclastogenesis by mediating ROS generation. Cell Biochem. Funct. 37 (4), 256-265. doi: $10.1002 /$ cbf.3394

Rowland, C. R., Glass, K. A., Ettyreddy, A. R., Gloss, C. C., Matthews, J. R. L., Huynh, N. P. T., et al. (2018). Regulation of decellularized tissue remodeling via scaffold-mediated lentiviral delivery in anatomically-shaped osteochondral constructs. Biomaterials 177, 161-175. doi: 10.1016/j.biomaterials.2018.04.049

Sarasam, A. R., Krishnaswamy, R. K., and Madihally, S. V. (2006). Blending chitosan with polycaprolactone: effects on physicochemical and antibacterial properties. Biomacromolecules 7 (4), 1131-1138. doi: 10.1021/bm050935d

Seenprachawong, K., Tawornsawutruk, T., Nantasenamat, C., Nuchnoi, P., Hongeng, S., and Supokawej, A. (2018). miR-130a and miR-27b enhance osteogenesis in human bone marrow mesenchymal stem cells via specific down-regulation of peroxisome proliferator-activated receptor gamma. Front. Genet. 9, 543. doi: 10.3389/fgene.2018.00543

Seidl, C. I., Martinez-Sanchez, A., and Murphy, C. L. (2016). Derepression of MicroRNA-138 contributes to loss of the human articular chondrocyte phenotype. Arthritis Rheumatol. 68 (2), 398-409. doi: 10.1002/art.39428

Seo, S. J., Mahapatra, C., Singh, R. K., Knowles, J. C., and Kim, H. W. (2014). Strategies for osteochondral repair: focus on scaffolds. J. Tissue Eng. 5, 2041731414541850. doi: 10.1177/2041731414541850

Sheng, J., Liu, D., Kang, X., Chen, Y., Jiang, K., and Zheng, W. (2018). Egr-1 increases angiogenesis in cartilage via binding Netrin-1 receptor DCC promoter. J. Orthop. Surg. Res. 13 (1), 125. doi: 10.1186/s13018-018-0826-x

Shi, S., Chan, A. G., Mercer, S., Eckert, G. J., and Trippel, S. B. (2014). Endogenous versus exogenous growth factor regulation of articular chondrocytes. J. Orthop. Res. 32 (1), 54-60. doi: 10.1002/jor.22444
Shimomura, K., Moriguchi, Y., Murawski, C. D., Yoshikawa, H., and Nakamura, N. (2014). Osteochondral tissue engineering with biphasic scaffold: current strategies and techniques. Tissue Eng. Part B. Rev. 20 (5), 468-476. doi: 10.1089/ ten.TEB.2013.0543

Song, J., Jin, E. H., Kim, D., Kim, K. Y., Chun, C. H., and Jin, E. J. (2015). MicroRNA-222 regulates MMP-13 via targeting HDAC-4 during osteoarthritis pathogenesis. BBA Clin. 3, 79-89. doi: 10.1016/ j.bbacli.2014.11.009

Sul, O. J., Rajasekaran, M., Park, H. J., Suh, J. H., and Choi, H. S. (2019). MicroRNA-29b enhances osteoclast survival by targeting BCL-2-modifying factor after lipopolysaccharide stimulation. Oxid. Med. Cell Longev. 2019, 6018180. doi: 10.1155/2019/6018180

Sun, L., Li, H., Qu, L., Zhu, R., Fan, X., Xue, Y., et al. (2014). Immobilized lentivirus vector on chondroitin sulfate-hyaluronate acid-silk fibroin hybrid scaffold for tissue-engineered ligament-bone junction. BioMed. Res. Int. 2014, 816979. doi: $10.1155 / 2014 / 816979$

Sun, L., Lian, J. X., and Meng, S. (2019a). MiR-125a-5p promotes osteoclastogenesis by targeting TNFRSF1B. Cell Mol. Biol. Lett. 24, 23. doi: 10.1186/s11658-019-0146-0

Sun, Q., Zhang, B., Zhu, W., Wei, W., Ma, J., and Tay, F. R. (2019b). A potential therapeutic target for regulating osteoporosis via suppression of osteoclast differentiation. J. Dent. 82, 91-97. doi: 10.1016/j.jdent.2019.01.015

Taipaleenmaki, H. (2018). Regulation of bone metabolism by microRNAs. Curr. Osteoporos. Rep. 16 (1), 1-12. doi: 10.1007/s11914-018-0417-0

Tang, J., Zhang, Z., Jin, X., and Shi, H. (2018). miR-383 negatively regulates osteoblastic differentiation of bone marrow mesenchymal stem cells in rats by targeting Satb2. Bone 114, 137-143. doi: 10.1016/j.bone.2018.06.010

Thomas, E., Peat, G., and Croft, P. (2014). Defining and mapping the person with osteoarthritis for population studies and public health. Rheumatol. (Oxford) 53 (2), 338-345. doi: 10.1093/rheumatology/ket346

Tian, Y., Guo, R., Shi, B., Chen, L., Yang, L., and Fu, Q. (2016). MicroRNA-30a promotes chondrogenic differentiation of mesenchymal stem cells through inhibiting Delta-like 4 expression. Life Sci. 148, 220-228. doi: 10.1016/ j.lfs.2016.02.031

Tsezou, A. (2014). Osteoarthritis year in review 2014: genetics and genomics. Osteoarthr. Cartil. 22 (12), 2017-2024. doi: 10.1016/j.joca.2014.07.024

Venkatesan, J. K., Gardner, O., Rey-Rico, A., Eglin, D., Alini, M., Stoddart, M. J., et al. (2018). Improved chondrogenic differentiation of rAAV SOX9-modified human MSCs seeded in fibrin-polyurethane scaffolds in a hydrodynamic environment. Int. J. Mol. Sci. 19 (9), 2635. doi: 10.3390/ijms19092635

Verbus, E. A., Kenyon, J. D., Sergeeva, O., Awadallah, A., Yuan, L., Welter, J. F., et al. (2017). Expression of miR-145-5p during chondrogenesis of mesenchymal stem cells. J. Stem Cell Res. (Overl Park) 1 (3), 1-10. doi: 10.33425/2639-9512.1017

Wang, X., Wenk, E., Zhang, X., Meinel, L., Vunjak-Novakovic, G., and Kaplan, D. L. (2009). Growth factor gradients via microsphere delivery in biopolymer scaffolds for osteochondral tissue engineering. J. Control Release 134 (2), 81-90. doi: 10.1016/ j.jconrel.2008.10.021

Wang, X., Li, Y., Han, R., He, C., Wang, G., Wang, J., et al. (2014). Demineralized bone matrix combined bone marrow mesenchymal stem cells, bone morphogenetic protein-2 and transforming growth factor-beta3 gene promoted pig cartilage defect repair. PloS One 9 (12), el16061. doi: 10.1371/ journal.pone.0116061

Wang, G., Zhang, Y., Zhao, X., Meng, C., Ma, L., and Kong, Y. (2015). MicroRNA411 inhibited matrix metalloproteinase 13 expression in human chondrocytes. Am. J. Transl. Res. 7 (10), 2000-2006.

Wang, J., Chen, L., Jin, S., Lin, J., Zheng, H., Zhang, H., et al. (2016). MiR-98 promotes chondrocyte apoptosis by decreasing Bcl-2 expression in a rat model of osteoarthritis. Acta Biochim. Biophys. Sin. (Shanghai) 48 (10), 923-929. doi: 10.1093/abbs/gmw084

Wang, C., Hou, W., Guo, X., Li, J., Hu, T., Qiu, M., et al. (2017). Two-phase electrospinning to incorporate growth factors loaded chitosan nanoparticles into electrospun fibrous scaffolds for bioactivity retention and cartilage regeneration. Mater. Sci. Eng. C. Mater. Biol. Appl. 79, 507-515. doi: 10.1016/j.msec.2017.05.075

Wang, C., He, H., Wang, L., Jiang, Y., and Xu, Y. (2018a). Reduced miR-144-3p expression in serum and bone mediates osteoporosis pathogenesis by targeting RANK. Biochem. Cell Biol. 96 (5), 627-635. doi: 10.1139/bcb-2017-0243 
Wang, W., Yang, L., Zhang, D., Gao, C., Wu, J., Zhu, Y., et al. (2018b). MicroRNA218 negatively regulates osteoclastogenic differentiation by repressing the nuclear factor-kappaB signaling pathway and targeting tumor necrosis factor receptor 1. Cell Physiol. Biochem. 48 (1), 339-347. doi: 10.1159/000491740

Wang, Y., Wang, K., Hu, Z., Zhou, H., Zhang, L., Wang, H., et al. (2018c). MicroRNA-139-3p regulates osteoblast differentiation and apoptosis by targeting ELK1 and interacting with long noncoding RNA ODSM. Cell Death Dis. 9 (11), 1107. doi: 10.1038/s41419-018-1153-1

Wang, C., Feng, N., Chang, F., Wang, J., Yuan, B., Cheng, Y., et al. (2019a). Injectable cholesterol-enhanced stereocomplex polylactide thermogel loading chondrocytes for optimized cartilage regeneration. Adv. Health Mater. 8 (14), e1900312. doi: 10.1002/adhm.201900312

Wang, X. B., Zhao, F. C., Yi, L. H., Tang, J. L., Zhu, Z. Y., Pang, Y., et al. (2019b). MicroRNA-21-5p as a novel therapeutic target for osteoarthritis. Rheumatol. (Oxford) 58 (8), 1485-1497. doi: 10.1093/rheumatology/kez102

Wei, Z. J., Liu, J., and Qin, J. (2017). miR-138 suppressed the progression of osteoarthritis mainly through targeting p65. Eur. Rev. Med. Pharmacol. Sci. 21 (9), 2177-2184.

Wu, Z., Qiu, X., Gao, B., Lian, C., Peng, Y., Liang, A., et al. (2018). Melatoninmediated miR-526b-3p and miR-590-5p upregulation promotes chondrogenic differentiation of human mesenchymal stem cells. J. Pineal Res. 65 (1), e12483. doi: $10.1111 /$ jpi.12483

Xia, W., Jin, Y. Q., Kretlow, J. D., Liu, W., Ding, W., Sun, H., et al. (2009). Adenoviral transduction of hTGF-betal enhances the chondrogenesis of bone marrow derived stromal cells. Biotechnol. Lett. 31 (5), 639-646. doi: 10.1007/ s10529-009-9930-7

Xia, P., Gu, R., Zhang, W., Shao, L., Li, F., Wu, C., et al. (2019). MicroRNA-200c promotes osteogenic differentiation of human bone mesenchymal stem cells through activating the $\mathrm{AKT} /$ beta-catenin signaling pathway via downregulating Myd88. J. Cell Physiol. 234 (12), 22675-22686. doi: 10.1002/jcp.28834

Xue, Z., Meng, Y., and Ge, J. (2017). miR-127-5p promotes chondrogenic differentiation in rat bone marrow mesenchymal stem cells. Exp. Ther. Med. 14 (2), 1481-1486. doi: 10.3892/etm.2017.4711

Xue, J., Min, Z., Xia, Z., Cheng, B., Lan, B., Zhang, F., et al. (2018). The hsa-miR$181 \mathrm{a}-5 \mathrm{p}$ reduces oxidation resistance by controlling SECISBP2 in osteoarthritis. BMC Musculoskelet. Disord. 19 (1), 355. doi: 10.1186/s12891-018-2273-6

Xue, H., Tu, Y., Ma, T., Wen, T., Yang, T., Xue, L., et al. (2019). miR-93-5p attenuates IL-1beta-induced chondrocyte apoptosis and cartilage degradation in osteoarthritis partially by targeting TCF4. Bone 123, 129-136. doi: 10.1016/ j.bone.2019.03.035

Yang, B., Ni, J., Long, H., Huang, J., Yang, C., and Huang, X. (2018a). IL-1betainduced miR-34a up-regulation inhibits Cyr61 to modulate osteoarthritis chondrocyte proliferation through ADAMTS-4. J. Cell Biochem. 119 (10), 7959-7970. doi: 10.1002/jcb.26600

Yang, S., Zhang, W., Cai, M., Zhang, Y., Jin, F., Yan, S., et al. (2018b). Suppression of bone resorption by miR-141 in aged rhesus monkeys. J. Bone Miner. Res. 33 (10), 1799-1812. doi: 10.1002/jbmr.3479

Yang, S., Qian, Z., Liu, D., Wen, N., Xu, J., and Guo, X. (2019). Integration of C-type natriuretic peptide gene-modified bone marrow mesenchymal stem cells with chitosan/silk fibroin scaffolds as a promising strategy for articular cartilage regeneration. Cell Tissue Bank 20 (2), 209-220. doi: 10.1007/s10561-019-09760-z

Yi, O., Kwon, H. J., Kim, H., Ha, M., Hong, S. J., Hong, Y. C., et al. (2012). Effect of environmental tobacco smoke on atopic dermatitis among children in Korea. Environ. Res. 113, 40-45. doi: 10.1016/j.envres.2011.12.012

Yin, X., Wang, J. Q., and Yan, S. Y. (2017). Reduced miR26a and miR26b expression contributes to the pathogenesis of osteoarthritis via the promotion of p65 translocation. Mol. Med. Rep. 15 (2), 551-558. doi: 10.3892/mmr.2016.6035

Yin, N., Zhu, L., Ding, L., Yuan, J., Du, L., Pan, M., et al. (2019). MiR-135-5p promotes osteoblast differentiation by targeting HIF1AN in MC3T3-E1 cells. Cell Mol. Biol. Lett. 24, 51. doi: 10.1186/s11658-019-0177-6
Yu, F. Y., Xie, C. Q., Sun, J. T., Peng, W., and Huang, X. W. (2018). Overexpressed miR-145 inhibits osteoclastogenesis in RANKL-induced bone marrow-derived macrophages and ovariectomized mice by regulation of Smad3. Life Sci. 202, 11-20. doi: 10.1016/j.lfs.2018.03.042

Zhang, H., Zhou, L., and Zhang, W. (2014). Control of scaffold degradation in tissue engineering: a review. Tissue Eng. Part B. Rev. 20 (5), 492-502. doi: 10.1089/ten.TEB.2013.0452

Zhang, X. H., Geng, G. L., Su, B., Liang, C. P., Wang, F., and Bao, J. C. (2016a). MicroRNA-338-3p inhibits glucocorticoid-induced osteoclast formation through RANKL targeting. Genet. Mol. Res. 15 (3), gmr.15037674. doi: 10.4238/gmr.15037674

Zhang, Y., Dong, R., Park, Y., Bohner, M., Zhang, X., Ting, K., et al. (2016b). Controlled release of NELL-1 protein from chitosan/hydroxyapatitemodified TCP particles. Int. J. Pharm. 511 (1), 79-89. doi: 10.1016/ j.ijpharm.2016.06.050

Zhang, Y., Huang, X., and Yuan, Y. (2017). MicroRNA-410 promotes chondrogenic differentiation of human bone marrow mesenchymal stem cells through down-regulating Wnt3a. Am. J. Transl. Res. 9 (1), 136-145.

Zhang, W., Cheng, P., Hu, W., Yin, W., Guo, F., Chen, A., et al. (2018). Inhibition of microRNA-384-5p alleviates osteoarthritis through its effects on inhibiting apoptosis of cartilage cells via the NF-kappaB signaling pathway by targeting SOX9. Cancer Gene Ther. 25 (11-12), 326-338. doi: 10.1038/s41417-018-0029-y

Zhang, Y., Yu, J., Ren, K., Zuo, J., Ding, J., and Chen, X. (2019). Thermosensitive hydrogels as scaffolds for cartilage tissue engineering. Biomacromolecules 20 (4), 1478-1492. doi: 10.1021/acs.biomac.9b00043

Zhao, J., Huang, M., Zhang, X., Xu, J., Hu, G., Zhao, X., et al. (2019a). MiR-146a deletion protects from bone loss in OVX mice by suppressing RANKL/OPG and M-CSF in bone microenvironment. J. Bone Miner. Res. 34 (11), 21492161. doi: 10.1002/jbmr.3832

Zhao, J., Liu, S., Zhang, W., Ni, L., Hu, Z., Sheng, Z., et al. (2019b). MiR-128 inhibits the osteogenic differentiation in osteoporosis by down-regulating SIRT6 expression. Biosci. Rep. 39 (9), BSR20191405. doi: 10.1042/ BSR20191405

Zheng, X., Zhao, F. C., Pang, Y., Li, D. Y., Yao, S. C., Sun, S. S., et al. (2017). Downregulation of miR-221-3p contributes to IL-1beta-induced cartilage degradation by directly targeting the SDF1/CXCR4 signaling pathway. J. Mol. Med. (Berl.) 95 (6), 615-627. doi: 10.1007/s00109-017-1516-6

Zheng, X., Dai, J., Zhang, H., and Ge, Z. (2018). MicroRNA-221 promotes cell proliferation, migration, and differentiation by regulation of ZFPM2 in osteoblasts. Braz. J. Med. Biol. Res. 51 (12), e7574. doi: 10.1590/1414$431 \mathrm{X} 20187574$

Zhou, L., Song, H. Y., Gao, L. L., Yang, L. Y., Mu, S., and Fu, Q. (2019a). MicroRNA1005p inhibits osteoclastogenesis and bone resorption by regulating fibroblast growth factor 21. Int. J. Mol. Med. 43 (2), 727-738. doi: 10.3892/ ijmm.2018.4017

Zhou, Z., Lu, Y., Wang, Y., Du, L., Zhang, Y., and Tao, J. (2019b). Let-7c regulates proliferation and osteodifferentiation of human adipose-derived mesenchymal stem cells under oxidative stress by targeting SCD-1. Am. J. Physiol. Cell Physiol. 316 (1), C57-C69. doi: 10.1152/ajpcell.00211.2018

Conflict of Interest: The authors declare that the research was conducted in the absence of any commercial or financial relationships that could be construed as a potential conflict of interest.

Copyright (c) 2020 Yan, Chen, Song, Yang, Ye, Zhou and Yu. This is an open-access article distributed under the terms of the Creative Commons Attribution License (CC BY). The use, distribution or reproduction in other forums is permitted, provided the original author(s) and the copyright owner(s) are credited and that the original publication in this journal is cited, in accordance with accepted academic practice. No use, distribution or reproduction is permitted which does not comply with these terms. 